\title{
Stonewalling in the Brick City: Perceptions of and Experiences with Seeking Police Assistance among LGBTQ Citizens
}

\author{
Danielle M. Shields
}

check for updates

Citation: Shields, Danielle M. 2021 Stonewalling in the Brick City: Perceptions of and Experiences with Seeking Police Assistance among LGBTQ Citizens. Social Sciences 10: 16. https://doi.org/10.3390/ socsci10010016

Received: 4 December 2020 Accepted: 4 January 2021 Published: 11 January 2021

Publisher's Note: MDPI stays neutral with regard to jurisdictional clai$\mathrm{ms}$ in published maps and institutional affiliations.

Copyright: (C) 2021 by the author. Licensee MDPI, Basel, Switzerland. This article is an open access article distributed under the terms and conditions of the Creative Commons Attribution (CC BY) license (https:// creativecommons.org/licenses/by/ $4.0 /)$.
School of Criminal Justice, Rutgers University-Newark, Newark, NJ 07102, USA; Danielle.Shields@rutgers.edu
Abstract: Extant research has documented police interactions between racial and ethnic minority populations, including negative perceptions of and experiences with the police; police corruption and misconduct; and the deleterious effects of negative relationships with the police, such as reduced legitimacy and mistrust. Comparatively, exchanges between lesbian, gay, bisexual, trans, and queer (LGBTQ) populations and the police have received limited attention. This is despite work suggesting that LGBTQ citizens face an elevated risk of victimization, and a possible reticence in reporting their victimization, resulting from negative perceptions of police, fear of mistreatment, or even experiences of harassment and abuse by police. To extend the research in this area, I analyze 12 focus groups with LGBTQ participants $(N=98)$ in an urban setting to examine the circumstances in which LGBTQ people would seek assistance from the police, when they would avoid doing so, and their justifications for avoiding or contacting the police. I also considered intersectionality in shaping police-citizen interactions between sexual and/or gender minority citizens of color, as the sample was almost exclusively LGBTQ persons of color. I conclude by discussing implications for policing practices and policies.

Keywords: sexuality; gender identity; gender; race/ethnicity; police practice; police policy; focus groups

\section{Introduction}

Over the past several decades, the relative status of LGBTQ people in the United States has undergone a significant evolution with a gradual and consistent movement towards increased equality and expanded integration into mainstream society (McCarthy 2019). Though progress has been achieved, LGBTQ identities have been largely overlooked in the field of criminology (Buist and Stone 2014). Outside of studies on anti-LGBTQ bias crimes, LGBTQ intimate partner violence (IPV), and the bullying of LGBTQ students in school settings, significant gaps persist concerning sexual orientation and gender identity [SOGI] minorities in criminological contexts (Woods 2014). Though scholars have begun to bridge this gap (Panfil and Miller 2014), the relevance of sexual orientation and/or gender identity has not yet permeated the criminal justice system via consistent, culturally competent, and inclusive training, policies, and day-to-day operations (Israel et al. 2016).

The approach taken by the criminal justice system in relationship to SOGI minorities is problematic for several reasons. First, LGBTQ citizens represent a significant proportion of the United States' population. More conservative estimates have indicated about 5.8 million LGBTQ people are in the U.S., comparable to the populations of states such as Wisconsin, Colorado, or Minnesota; others have suggested upwards of 25 million U.S. LGBTQ people, a figure comparable to the size of Florida or New York (Deschamps and Singer 2017; United States Census Bureau 2019). Second, LGBTQ people are also more likely to identify as racial and ethnic minorities relative to their heterosexual counterparts (Deschamps and Singer 2017). These sociodemographic patterns are cause for concern because of the already well-documented disparate treatment of people of color in the criminal justice system (Tonry 2010), which may be compounded by status as a SOGI minority (Mogul et al. 
2011). Third, LGBTQ people are overrepresented throughout the criminal justice system (Meyer et al. 2017). As a result, SOGI minorities have increased odds of contact with law enforcement personnel who likely lack appropriate training to sensitively interact with them. Thus, culturally competent approaches are essential to produce increased trust and improved victimization reporting among LGBTQ communities.

Law enforcement is the most visible part of the American criminal justice system and is the first point of contact for those in need of assistance. As part of their professional and ethical obligations to the communities they serve, it is incumbent upon police officers to equitably engage with LGBTQ citizens, including in situations such as anti-LGBTQ bias crimes or IPV. However, research has consistently shown that LGBTQ citizens have poor perceptions of the police (Dario et al. 2019; Owen et al. 2018; Nadal et al. 2015; Satuluri and Nadal 2018), report personal experiences with police harassment and misconduct (Hodge and Sexton 2018; James et al. 2016; NCVAP 2017a, 2017b; Wolff and Cokely 2007), and experience problematic police responses to IPV (Guadalupe-Diaz 2016; Messinger 2017) and anti-LGBTQ bias crimes (Berrill and Herek 1992; Stotzer 2014a). In addition, research demonstrates a pattern of adverse police treatment of transgender people (Grant et al. 2011; Guadalupe-Diaz 2016; Miles-Johnson 2020; Miles-Johnson 2016; Stotzer 2014b; Woods et al. 2013) who also hold particularly pronounced negative views of the police (Dario et al. 2019; Owen et al. 2018; Serpe and Nadal 2017). Research also finds unsatisfactory police interactions with LGBTQ youth (Dwyer 2007; Feinstein et al. 2001; Holsinger and Hodge 2016) and disparate treatment of LGBTQ people of color (Amnesty International USA 2005; Center for American Progress 2016; Gaynor and Bassett 2020; James et al. 2016; Woods et al. 2013).

The findings of prior research are significant, as poor regard for the police and/or adverse prior experiences can undermine trust and cement an unwillingness to report victimization (Berrill and Herek 1992; Guadalupe-Diaz 2016; Xie et al. 2007) that may be elevated among LGBTQ people (Miles-Johnson 2013b). Furthermore, LGBTQ subpopulations such as gay men (Herek 2009), trans people (Grant et al. 2011; Stotzer 2014a), and people of color (Dunbar 2006; Kuehnle and Sullivan 2001; Meyer 2010; NCVAP 2017a, 2017b) are especially vulnerable to victimization, and thus, are in particular need of supportive police interactions. Hence, there is an ongoing need to better understand the attitudes LGBTQ people hold towards the police and the nature of their contacts with police-particularly with respect to vulnerable sub-populations.

This study aims to make a timely contribution to the literature by investigating why LGBTQ citizens may be dissuaded from seeking police assistance. I rely on an intersectional framework to examine these nuances by utilizing focus groups with a sample comprised of multiply-marginalized groups from an urban, under-resourced, and crime-prone setting. I discuss my findings through participants' narratives of their perceptions, experiences, and reporting behaviors with police officers. I conclude with policy implications raised by the study and make recommendations for future research.

\subsection{Victimization and Reporting Behaviors among LGBTQ Citizens}

Among the general population in the United States, it appears that a significant proportion of victims opt out of reporting crimes to the police. According to estimates constructed by the National Crime Victimization Survey (NCVS), the majority of crimes (58\%) were unreported from 2006 to 2010, including half (52\%) of all violent crimes (Langton et al. 2012). Most commonly, people who did not disclose their victimization reported they handled the incident outside of the justice system and/or believed it was private in nature (34\%) or felt their victimization was too minor to warrant police involvement (18\%). They also doubted that the police would be capable of providing effective assistance $(16 \%)$ or conveyed concerns related to the offender's punishment and their potential to enact revenge (13\%) (Langton et al. 2012). Extrapolating from this work, these concerns will likely also be present-and perhaps even more salient_among LGBTQ people based on various documented adverse interactions with the police (Amnesty International USA 2005; Hodge 
and Sexton 2018; James et al. 2016; Lambda Legal 2015; Mallory et al. 2015; Stotzer 2014b; Wolff and Cokely 2007; Woods et al. 2013) that may prevent them from contacting police initially (Miles-Johnson 2013b) or if victimized once more (e.g., Xie et al. 2007). Indeed, work conducted with LGBTQ people specifically has suggested unique reservations that shape their decision-making regarding crime reporting, such as feelings of fear, self-blame, and practical barriers to reporting (Briones-Robinson et al. 2016; Peel 1999). In a comparative analysis, Miles-Johnson (2013b) also found LGBTQ people were less likely to seek assistance from the police compared to their heterosexual counterparts and that the anticipation of homophobic treatment functioned as a significant deterrent in doing so.

The LGBTQ community experiences various forms of victimization that should, in theory, warrant police intervention, including general crimes, bias crimes, and IPV. Fundamentally, it appears SOGI minorities are victimized more frequently than heterosexual people (Katz-Wise and Hyde 2012). Prior work has estimated that up to 55 percent of LGB people have experienced verbal, physical, or sexual victimization (Berrill 1993; Berrill and Herek 1992; Herek 2009; Huebner et al. 2004; Herek et al. 2002), while as many as 50 percent of transgender people have experienced physical or sexual victimization (James et al. 2016; Stotzer 2009). Furthermore, official estimates indicate one-fifth to one-quarter of bias-related crimes are due to sexual orientation or gender identity; most of these offenses $(73 \%)$ are violent in nature, including physical assaults and forcible rape (Federal Bureau of Investigation 2018a; Oudekerk 2019; Masucci and Langton 2017). Other work has estimated the majority (roughly 60 percent) of trans people have been violently victimized based solely on their SOGI status (Lombardi et al. 2001) and are over two times more likely to be sexually attacked relative to lesbian women, gay men, and bisexual cisgender people (Langenderfer-Magruder et al. 2016b). IPV is also prevalent in the LGBTQ community, resembling or even exceeding rates found among heterosexual couples (Courvant and Cook-Daniels 1998; Messinger 2017; Turell 2000), with LGB people of color, transgender people, and bisexual people at particular risk (Guadalupe-Diaz and Yglesias 2013; James et al. 2016; Langenderfer-Magruder et al. 2016a; NCVAP 2017b; Rollè et al. 2018; Turell et al. 2017; Whitfield et al. 2018).

Despite victimization trends among LGBTQ people, some work has indicated there may be gaps in their reporting behaviors (Miles-Johnson 2013b; Peel 1999). For instance, although victimization among SOGI minorities may be especially prominent (e.g., KatzWise and Hyde 2012) it appears reporting rates may be lower among this population in relationship to bias-related victimizations (Herek et al. 1992, 2002; Pezella et al. 2019; Stotzer 2014a) and IPV (Aulivola 2004; Langenderfer-Magruder et al. 2016a; Miles-Johnson 2020; NCVAP 2017b). Furthermore, the National Coalition of Anti-Violence Programs (NCVAP) recently estimated that the majority of anti-LGBTQ bias crimes (58\%) and IPV incidents (59\%) were unreported to police (NCVAP 2017a, 2017b), despite a higher prevalence amongst LGBTQ people of color relative to their white counterparts. According to Stotzer's (2014b) review, trans victims are especially hesitant to contact the police, with non-reporting rates ranging from $40 \%$ to as high as $90 \%$. Overall, these patterns suggest significant gaps in reporting among LGBTQ citizens, closing an important mechanism for addressing LGBTQ victimization. To facilitate increased reporting rates, officers must be willing to respond to such victims in a culturally competent manner rather than with disdain, indifference, or various forms of misconduct (e.g., Israel et al. 2016; NCVAP 2017a, 2017b; Wolff and Cokely 2007).

\subsection{LGBTQ Communities and Perceptions of the Police}

Broadly speaking, LGBTQ communities appear to harbor distrust towards law enforcement (Hodge and Sexton 2018; Herek et al. 1992; Berrill 1993) that outpaces that of heterosexual (Owen et al. 2018; Satuluri and Nadal 2018) and cisgender ${ }^{1}$ (Serpe and Nadal

1 According to the Human Rights Campaign (2014), the term cisgender refers to "people whose gender identity or expression aligns with those typically associated with the sex assigned to them at birth" (p. 16). 
2017) people. In one analysis, LGBTQ participants were less likely to view the police as friendly, impartial, and non-discriminatory than heterosexual people (Satuluri and Nadal 2018). Dario et al. (2019) found that LGBTQ participants were more likely than heterosexual participants to report unfavorable perceptions of police legitimacy. Similarly, Owen et al. (2018) reported that LGBTQ people more frequently felt police treated their community unfairly and were less satisfied with police efficiency and services than their heterosexual counterparts. In both studies, trans participants reported particularly low regard for the police compared to cisgender people (see also Miles-Johnson 2013a; Serpe and Nadal 2017). Prior work also suggests LGBTQ citizens are concerned their complaints may not receive serious attention from officers (Bernstein and Kostelac 2002; Guadalupe-Diaz and Jasinski 2017; Herek et al. 2002; Kuehnle and Sullivan 2001) or will not be recorded at all (Wolff and Cokely 2007).

Research has also gauged anti-LGBTQ attitudes and behaviors among law enforcement by directly surveying and interviewing police officers (e.g., Bernstein and Swartwout 2012; Colvin 2012, 2009a, 2009b; Lyons et al. 2008; Lyons et al. 2005; Panter 2018). It appears police officers are routinely exposed to culturally-entrenched homophobia, anti-gay stereotypes, and discriminatory behaviors endorsed and/or performed by their co-workers and superiors (Colvin 2009a, 2009b; Lyons et al. 2008; Miller et al. 2003). Mallory et al. (2013) revealed anti-LGBTQ discrimination within police departments is ubiquitous, producing reduced opportunities for promotion, potential dismissal, and verbal, physical, and/or sexual harassment enacted by fellow officers. Among a sample of heterosexual officers, one-third agreed gay men "are disgusting" (Lyons et al. 2005, p. 9). Similarly, in a survey of police chiefs, half (49\%) disclosed discomfort at the prospect of a gay male co-worker (Lyons et al. 2008). Bernstein and Kostelac (2002) also found evidence of anti-LGBTQ sentiments among police officers, as roughly half of heterosexual officers believed LGBTQ citizens received differential treatment and that LGBTQ-related incidents were treated less seriously. These patterns have likely lingered due to the "masculinized" nature of policing (Collins and Rocco 2018, p. 1) and cultural prescriptions that officers should embrace these stereotypes (Colvin 2014). Panter (2018) asserted that policing culture prizes a traditional gender binary, wherein masculinity is a measuring rod for perceived success as a police officer; as a result, transgender and gender nonconforming police officers may be especially impacted by these aspects of policing and face transphobic treatment. The impact of policing culture is an important consideration, as it may have ramifications for how officers may behave during interactions with citizens (Ingram et al. 2018).

\subsection{The LGBTQ Community and Experiences with the Police}

Reporting behavior is inextricably bound, not just with perceptions of the police, but police officers' actual behaviors. For instance, negative regard for the police may stem from prior adverse interactions (Herek et al. 2002; Moran and Sharpe 2004; Serpe and Nadal 2017; Stotzer 2014a; Wolff and Cokely 2007). The dismal perceptions of police within LGBTQ communities appear to have merit, as available research suggests these communities are routinely exposed to police mistreatment. Studies have documented the exposure of LGBTQ citizens to discourtesy, indifference, hostility, homophobia and/or transphobia, and verbal, sexual, and/or physical harassment from officers, as well as other barriers to service such as the refusal to file a report (Lambda Legal 2015; Mallory et al. 2015; NCVAP 2017a, 2017b; Wolff and Cokely 2007). According to the NCVAP, during 2017, a significant portion of anti-LGBTQ bias or IPV victims described responding officers as "indifferent" (55\%) or "hostile" (20\%) (NCVAP 2018, p. 56). Additionally, Wolff and Cokely (2007) found LGBT-police interactions were negative more often than not, with one in four of these interactions involving police misconduct, including harassment, threats, and physical violence, while one-third of officers failed to document citizens' complaints. More recently, Hodge and Sexton (2018) generated similar findings, as roughly half of their sample $(49 \%)$ reported harassment from officers. 
Interactions between the trans community and the police appear to be particularly troubled (Hodge and Sexton 2018; James et al. 2016; Mallory et al. 2015). Stotzer's (2014b) review of research on trans people and their victimization by the police uncovered various forms of police misconduct, including biased treatment as well as verbal, physical, or sexual abuse. Furthermore, trans women who are simply navigating public spaces or performing targeted outreach work (e.g., distributing free condoms) regularly face the threat of arrest for solicitation - an action that illustrates "transwomen are routinely profiled" as sex workers by law enforcement (Amnesty International USA 2005; Carpenter and Marshall 2017; Center for Constitutional Rights 2012, pp. 12-13; Panter 2018), particularly if they are women of color (James et al. 2016). Thus, it is unsurprising that trans victims of IPV may be less likely to seek assistance from the police based on poor prior experiences with officers (Guadalupe-Diaz 2016). Unfortunately, it appears tensions with police officers dissuade trans women from seeking the assistance of law enforcement, even when it is needed most.

\subsection{Intersectionality and Interactions between Police and LGBTQ Citizens}

A range of studies have indicated the troubled relationship between the LGBTQ community and the police may be particularly salient for SOGI people who are also racial and ethnic minorities (Dario et al. 2019; Gaynor and Bassett 2020; Graham 2014; Grant et al. 2011; Guadalupe-Diaz and Yglesias 2013; Hodge and Sexton 2018; James et al. 2016; Kuehnle and Sullivan 2001; Lambda Legal 2015; Mallory et al. 2015; Nadal et al. 2015; NCVAP 2017a, 2017b; Owen et al. 2018; Panfil 2018; Serpe and Nadal 2017). These challenges may translate into a further diminished likelihood of turning to the police when victimized. Fundamentally, an intersectional perspective argues that the combined impact of membership across multiple historically marginalized groups serves as an avenue to heighten, amplify, and multiply the social inequalities already separately experienced via individual identities (Crenshaw 1991a, 1991b). Namely, statuses associated with being a SOGI minority of color are not phenomena that exist independently in a vacuum, as "all social relations are racialized" (Burgess-Proctor 2006, p. 83). Difficulties due to multiply marginalized identities exist throughout macro and micro social structures and processes, including the criminal justice system and its actors. Thus, intersectionality can serve as a bridge in understanding the attitudes, beliefs, and experiences of LGBTQ populations and their interactions with the criminal justice system generally and the police specifically.

\section{Methods}

\subsection{Study Purpose and Research Questions}

Using an intersectional lens, this study aims to better understand police-citizen interactions with LGBTQ citizens of color situated in an economically disadvantaged, urban setting through a qualitative analysis of focus groups. Specifically, I provide an in-depth examination of LGBTQ participants' accounts of when they choose to rely on law enforcement and, perhaps more importantly, when they do not. By analyzing participants' perceptions of law enforcement, I seek to understand why LGBTQ citizens may be reluctant to contact police to report victimization or seek assistance from the police. I also endeavor to expand the literature regarding intersectional analysis by exploring how membership in multiple marginalized identities impacts police-citizen interactions and how these interactions differ between trans women, lesbian women, and gay men of color. Finally, this research has important implications for policy and practice, as it seeks to improve the relationship between LGBTQ communities of color and law enforcement by providing recommendations for targeted training and efforts to increase officers' cultural competency. Thus, I address the following research questions:

1. What are the circumstances and contexts in which participants describe that they would or would not seek assistance from the police?

2. What are participants' articulated reasons and rationales for avoiding or interacting with the police? 


\subsection{Study Setting and Background}

This study was conducted in Newark, New Jersey. With a population of roughly 282,000 , Newark is fairly economically deprived, with a household median income of only USD 35,000 and almost one-third (27\%) of its citizens living below the poverty line (United States Census Bureau 2019). The vast majority of the city's residents are African American (50\%) or Hispanic (36\%) (United States Census Bureau 2019). Newark is also known for its concentration of crime. During 2018, for example, its violent crime rate was over seven times the national average (Federal Bureau of Investigation 2018b). In terms of services oriented towards the LGBTQ community, Newark is also unique, as it is home to approximately 6 community-based organizations that specifically target and serve LGBTQ youth, adults, and people of color (Essex LGBT Reaching Adolescents in Need 2017). Newark has also instituted and maintained an LGBTQ Advisory Commission that coordinates with Newark's mayor, Ras Baraka, who has supported other LGBTQ-related policies (Cagnassola 2020; The Citizens Campaign 2019; Rutgers School of Public Health 2019). Given its population composition and characteristics, Newark is a particularly wellsuited setting to investigate experiences with and perceptions of the police among LGBTQ citizens of color.

To fully gauge possible contextual characteristics that may shape citizens' evaluations of the Newark Police Department (NPD), it is important to understand its basic structure as well as the controversies it has faced. The NPD is among the 50 largest police departments in the United States (Kershner 2020) and is currently staffed by approximately 1100 sworn officers as of 2019 (Rahman 2019). It is also an active department, as it annually responds to more than half a million calls (Newark Department of Public Safety 2018). Relative to its population, Newark currently employs about 3.9 officers per 1000 residents (United States Census Bureau 2019), exceeding comparably sized cities that are served by 3.4 officers per 1000 citizens (Federal Bureau of Investigation 2020). It should be noted that factors closely related to satisfaction with the police, such as response times (Larsen and Blair 2009), may be significantly impacted by diminished staffing levels (McCabe and O'Connell 2017) as well as local political trends (Levitt 2002; Stucky 2005). Thus, though satisfaction with the police is related to the performance and behaviors of individual officers (e.g., Avdija 2010; Braga et al. 2014; Larsen and Blair 2009; Lee et al. 2014), because the economic resources available to police departments can significantly alter their day-to-day practices they may, by proxy, also impact citizens' regard for the police.

On this note, Smith and Cooper (2020) of the Vera Institute of Justice recently examined 72 large municipalities to determine staffing and budgetary trends. Their analysis revealed Newark's policing expenditures totaled roughly USD 208 million and comprised nearly one-third (29\%) of its budget as of 2019, matching the study's mean budgetary allocations $(29 \%)$. Notably, though its staffing for policing personnel was slightly lower than average (341 police employees per citizen vs. 358, respectively), Newark's spending rate per citizen for law enforcement services was nearly two times higher (USD 737 vs. USD 403). Based on the available data, it appears somewhat unclear if the NPD is appropriately funded and staffed, as such decision-making can be quite complex and there are a variety of methods to determine staffing needs (Wilson and Weiss 2014; Wilson et al. 2010). Others have argued that nationally, cities are generally inappropriately staffed with respect to law enforcement (Chalfin and McCrary 2016). Recently, in concert with calls nationwide to reduce police-related spending and downsize departments (Levin 2020), Newark has decided to redirect a small portion of its funding for law enforcement toward other city-wide services (Kieffer 2020).

However, the NPD has served as a lightning rod for controversy due to its established history of alleged and verified departmental misconduct (Ross 2019). In 2011, serious allegations waged against the NPD spurred an investigation by the Department of Justice (DOJ). Concluding its investigation in 2014, the DOJ's findings were a harsh indictment of the NPD, describing its actions as a model of "constitutional violations" (DOJ 2014, p. 1). It asserted officers had systematically engaged in a variety of unethical behaviors, 
including inappropriate "stop and arrest practices" and "use of force" as well as "theft by officers" (DOJ 2014, p. 1). Of particular concern, many of these practices disproportionately impacted black citizens relative to their white counterparts. The DOJ (2014) concluded these trends were likely exacerbated through a lack of oversight by administrators and a lack of accountability through internal affairs (Gerhardt 2016). As a result of the DOJ's findings, Newark has been subjected to federal monitoring through a consent decree that has been implemented since 2016 (Newark Police Division 2020).

The NPD has also amassed repeated allegations of improper conduct against LGBTQ citizens, as high-profile incidents featuring LGBTQ citizens precipitated the DOJ's investigation. For example, in 2010, the NPD was sued by the American Civil Liberties Union (ACLU) in representation of Diana Taylor, a transgender woman who alleged officers verbally abused and humiliated her as a result of her gender identity during a stop (Cavaliere 2010). Furthermore, Defarra Gaymon, a 48-year-old male, was shot and killed by an undercover police officer in 2010 in a park known for anonymous gay sex; in the wake of his death, outrage was directed towards the NPD for their repeated deployment of risky and unnecessary undercover sting operations to target gay men seeking anonymous sex (Wilson and Kovaleski 2010). More recently, the NPD has been accused of failing to aggressively investigate and sensitively handle homicide cases where the victim is a transgender woman (Tracy 2020). Thus, along with the revelation of more generalized patterns of misconduct enacted against Newark's citizens, the DOJ's report also noted "anecdotal evidence that the NPD has engaged in discriminatory policing practices based on sexual orientation or gender identity" (United States v. City of Newark 2016, p. 48).

In the aftermath of the DOJ's investigation, Newark has taken steps to ameliorate its documented deficiencies. In doing so, it has endeavored to meaningfully modify the NPD's policies (e.g., use of force, searches, and stops) (Shearn 2020). Newark has also instituted a range of LGBTQ-related policies and trainings designed to close the divide that has formed between the NPD and Newark's LGBTQ community. In addition to educating officers about the LGBTQ community through training, the NPD has also instituted new LGBTQ-specific policies; these changes include revised rules concerning interactions with transgender and gender nonconforming people and the appointment of an LGBTQ liaison officer to "serve as the contact point" between the LGBTQ community and the police (Ambrose 2019, p. 9; O'Dea 2019). As these reforms are still relatively nascent and evolving, their long-term impact remains to be seen and truly understood, particularly in the face of different perspectives on what constitutes true success in relationship to federal monitoring. For instance, critics have doubted Newark's ability to successfully enact significant reform, pointing out that it has repeatedly lagged behind the DOJ's timeline to implement officer trainings (Ross 2019). In contrast, in tandem with other public officials (Di Ionno 2020), Newark's current mayor has asserted several successful outcomes-such as fewer violent crimes and reports of police misconduct alongside increased oversight through internal affairs-are proof that the reforms implemented by the NPD have been impactful (Shearn 2020).

\subsection{Participants and Procedures}

A total of 12 focus group interviews were conducted with 98 participants, with a range of 5 to 12 participants per group. Interested parties were eligible to participate if they resided in the metropolitan Newark area ${ }^{2}$, identified as LGBTQ, and were over 18 years of age. Focus group sessions ranged from one to two hours and participants received a USD 25 stipend as compensation for their time. Each session was audio-recorded. To maintain confidentiality, participants selected and used pseudonyms during each group.

2 Participants from bordering municipalities were included due to their close geographic proximity and resemblance to Newark's sociodemographic and crime characteristics. Additionally, LGBTQ people from surrounding areas often spend time in Newark due to its various LGBTQ-related services and centers that are unavailable in their communities; as a result, they may develop close-knit, chosen fictive kinship networks (Muraco 2006). The study sample included 13 participants who lived in surrounding areas but indicated regular involvement with Newark's LGBTQ community and services; these areas included East Orange, Irvington, Elizabeth, Jersey City, Plainfield, Bloomfield, and Maplewood. 
Given challenges accessing Newark's LGBTQ population, participants were recruited using a snowball sampling strategy that relied on several sources embedded within the local LGBTQ community. Recruiters included staff at LGBTQ-related agencies ${ }^{3}$, key stakeholders and community leaders, and word of mouth. Eligible participants were invited to participate in focus groups held at various community centers throughout the city of Newark.

Subsequent to the first two focus groups $(N=13)$, study participants also completed a demographic questionnaire $\left(N=85^{4}\right)$. Surveyed participants ranged in age from 18 to 65 , with an average of 25 years of age. Of the 83 participants who disclosed their racial and ethnic identities, 65 identified as African American or Black (77\%), followed by 12 who identified as multi-racial (14\%), 3 as Hispanic ( $4 \%$ ) and an additional 3 who identified as "other" $(4 \%)$. Though most participants were born in the United States, $12(14 \%)$ indicated they were immigrants. The sample included participants with the following sexual orientations and gender identities: lesbian women $(N=28)$, gay men $(N=20)$, bisexual men and women $(N=8)$, transgender men $(N=4)$ and women $(N=17)$, and other sexual orientations and gender identities $(N=9)^{5}$.

Several moderators, including the author and a team of research assistants ${ }^{6}$, oversaw the focus groups. We guided participant discussions through a set of semi-structured, open-ended questions about a range of relevant topics (see Appendix A for the complete focus group interview guide). First, to build rapport and open up the group to discussion, participants were asked to give a broad overview of the LGBTQ community in Newark by asking, "Can you tell me a bit about the LGBTQ community in Newark?" Next, participants were asked to discuss their openness regarding sexual orientation and gender identity in their respective neighborhoods. Following these questions, participants were asked about situations in which they would and would not contact NPD. Participants were also asked about who they would first contact if they were the victim of an anti-LGBTQ bias crime as well as their perceptions of police treatment based on sexual orientation and gender identities. They were then asked to recall specific accounts of interactions with NPD through the questions, "Have you had any experiences, good or bad, with the Newark police?" and "What happened and what was your experience?" Finally, participants discussed ways NPD can improve its relationship with the LGBTQ community. They were encouraged to dialogue with one another throughout the process.

Table 1 shows the compositions of each focus group. While two groups (6 and 10) included only trans women, most included a mixture of participants with respect to sexual orientation and/or gender identity. Three groups $(1,8$, and 9) involved two participant categories, with two groups featuring one dominant category (e.g., group 8 , which featured 5 lesbian women and one bisexual woman). Five groups were more diverse $(2,3,4,5$, and 7) and represented three or more groups of participants.

3 It is possible that people who frequent these organizations may embrace their identities to a degree that distinguishes them from people who do not. As a result, their identification as an SOGI minority may be more salient and central to their overall sense of self.

4 Participants who took part in the first two focus groups are excluded from demographic tallies. In addition, five participants were interviewed in more than one focus group and are only counted once in this total.

5 The demographic questionnaire asked two separate questions to gauge participants' sexual orientation and gender identity. However, these questions did not adequately represent the complexities of identities that fall outside of conventionally defined categories of sexual orientation and/or gender identity, such as participants who identified as transgender women with respect to their gender identity and as gay men with respect to their sexual orientation; thus, these questions were of limited use in describing multi-faceted queer identities embraced by some transgender and other gender nonconforming participants based on their responses to these questions. To preserve these complexities, I have instead chosen to talk about these participants only in the context of their transgender or gender nonconforming identity, as it is the most salient aspect of these participants' interactions with the police. The category "other" is comprised of sexual orientations and/or gender identities that could not be merged with the groups presented in Table 1 for the aforementioned conceptual reasons.

6 Research assistants were trained by an expert in qualitative methodology on the dynamics of focus groups, moderating and interviewing techniques, and maintaining fidelity to the parameters of the focus group questionnaire. 
Table 1. Demographic Characteristics by Focus Group.

\begin{tabular}{|c|c|c|c|c|c|c|c|c|}
\hline \multicolumn{9}{|c|}{ Demographic Profiles of Participants and Participants by Group $(N=91 *)$} \\
\hline \multirow{2}{*}{ Group } & \multirow{2}{*}{$\begin{array}{l}\text { Number of } \\
\text { Participants }\end{array}$} & \multirow{2}{*}{$\begin{array}{l}\text { Lesbian } \\
\text { Women }\end{array}$} & \multirow{2}{*}{ Gay Men } & \multicolumn{2}{|c|}{ Bisexual } & \multicolumn{2}{|c|}{ Transgender } & \multirow{2}{*}{ Other $* *$} \\
\hline & & & & Women & Men & Trans Women & Trans Men & \\
\hline 1 & 11 & - & 9 & - & - & 2 & - & - \\
\hline 2 & 10 & - & 5 & - & 2 & 1 & - & 2 \\
\hline 3 & 7 & 4 & 1 & - & 1 & - & - & 1 \\
\hline 4 & 10 & 4 & - & 2 & - & - & 1 & 3 \\
\hline 5 & 10 & - & 6 & - & 1 & 2 & - & 1 \\
\hline 6 & 9 & - & - & - & - & 9 & - & - \\
\hline 7 & 10 & 6 & - & 1 & - & - & 2 & 2 \\
\hline 8 & 6 & 5 & - & 1 & - & - & - & - \\
\hline 9 & 11 & 9 & - & - & - & - & 1 & 1 \\
\hline 10 & 7 & - & - & - & - & 7 & - & - \\
\hline Total ** & 91 & 28 & 21 & 4 & 4 & 21 & 4 & 9 \\
\hline
\end{tabular}

* Participants from two initial pilot focus groups $(N=13)$ are excluded from this table, as they did not complete a demographic questionnaire and thus, this information is unavailable. ${ }^{* *}$ Additionally, five participants took part in multiple focus groups; four of these took part in two focus groups, while one was present for three focus groups. Thus, the total number of participants presented in Table 1 ( $N=91)$ is higher than the total number of participants referred to elsewhere in the manuscript $(N=85)$, as Table 1 reflects the distribution of the sample within each focus group, including the five participants who took part in multiple groups (two gay men and three trans women).

\subsection{Analytic Strategy}

After the data were transcribed verbatim, I performed a content analysis wherein participant narratives were first coded line-by-line to identify larger patterns, tracking the use of keywords, phrases, and themes that were repeatedly mentioned during each focus group. At this stage, participants' narratives were assigned a code in the margins of each group transcript, based on categories such as participants' evaluations of the performance of the police, general stereotypes and attitudes towards the police, and LGBTQ-specific experiences with mistreatment which were then grouped and renamed. For example, the circumstances in which participants would contact the police were counted and compared across the respective SOGI categories described above. Additionally, the number of experiences participants reported with the police as well as the overall nature and tone of these interactions based on participants' descriptions were tabulated and analyzed. For instance, participants' experiences with the police were categorized based on whether or not these experiences were negative or positive, with themes within these groupings then refined (i.e., the police were discourteous, indifferent, did not resolve their complaint, or engaged in other problematic behaviors; the police were friendly and/or participants expressed satisfaction with the interaction and why).

To extend and affirm the patterns revealed in the initial content analysis, a domain analysis (Spradley 1979) was also performed to further understand and categorize the types of situations in which participants would summon the police, when they would elect not to do so, and their reasoning for their decision. To identify prominent semantic relationships (i.e., $X$ is a reason for doing Y; see Spradley 1979) and domains, the types of situations in which participants would contact the police were tallied and categorized for the entire sample. These domains included situations participants repeatedly identified as appropriate for contacting the police, such as for violent crimes and serious forms of harassment and threats, along with repeated mentions of when not to contact the police. Upon identification of these patterns, representative quotes were chosen to demonstrate these semantic relationships. An analysis of deviant cases was also performed; for instance, in a departure from most of the sample, a handful of participants felt comfortable contacting the police under any circumstance and held positive regard for the police. Accordingly, these cases were analyzed in relation to the larger patterns to identify what might explain their differences. Both broader patterns and exceptional cases are discussed below. 


\section{Results}

The existing literature poses a uniquely troubling conundrum: as a product of negative perceptions of and/or experiences with law enforcement, some LGBTQ people refrain from contacting the police, even during precarious, unstable, or outright dangerous situations. Discomfort reporting victimization to law enforcement can jeopardize victims' well-being and allow the perpetrator(s) to face no legal accountability. Across the 12 focus groups, participants were asked to describe circumstances in which they would and would not ask the police for help. Their reporting behaviors fell into two categories: participants who would rarely or never seek help from the police and those who felt comfortable seeking help from police. There were not observable differences across LGBTQ identities in when participants would or would not contact police. Additionally, when participants described actually having made reports to the police, they did so for similar incidents. However, with the exception of one participant ${ }^{7}$, those who reported IPV $(N=9)$ were exclusively cisgender $(N=6)$ and transgender women $(N=2)$.

\subsection{When to Call Police}

Among the 43 participants who discussed whether and when they would contact the police, one-third indicated they would never seek police assistance. Of the remaining two-thirds, most indicated they would summon the police only under a narrow set of conditions. These included medical emergencies (32\%), violent incidents $(28 \%)$, and harassment and threats (24\%). Others gave vague responses like "it depends" (16\%). A number of participants viewed the police as an absolute last resort in life-or-death situations. For instance, Dana, an 18-year-old lesbian, stated she would only contact the police "If I'm dying." Valentina, an 18-year-old queer woman, pointed out that unless mortally wounded, she would pursue help outside of the police:

Aight, if I got shot but I could still walk, like, I didn't get shot in either of my legs, I'm going to walk myself to a hospital. I'm not going to ask a cop for help so I could get, like, a thousand dollars in like, medical bills from an ambulance ride ... Like (pause), like I got to be dying if I ask [the police] for help.

Notably, during a focus group exclusively with transgender women, participants said if they fought with a cisgender woman, their trans identity would become a focal point, warranting a need to preemptively reach out to the police. Ingrid (a 22-year-old), Shakia (a 23-year-old), and Charlene (a 50-year-old) explained:

Ingrid: So if I get in a altercation with a biological female, she feel like, she want to do something, I'm not gonna do that. I'm calling the cops ... Because if I touch her, then I know when the cops come-

Shakia: They gonna break it up-

Charlene: When they [police] do come ... if it was a fight between me and a biological female, I don't care if I had double D's, they gonna say, "You are a man" and they gonna lock me up.

Their dialogue suggests that preemptively contacting the police-rather than escalating to a physical altercation or allowing the cisgender woman to call the police-was important, as the police would fail to recognize them as women and instead treat them based on their gender assigned at birth.

While the majority of study participants were generally reticent to call the police, only 4 participants indicated they would be comfortable doing so under "any" circumstances, while a total of 12 participants reported positive interactions with the police. Natasha, a 19-year-old woman who identified as 'questioning,' explained, "I like Newark Police ... because whenever I had a problem, they helped me." Lamar, a 25-year-old gay man, emphatically stated, "[I call] the cops for everything. If I feel some type of way, I'm

7 This participant took place in one of the two pilot focus groups; as a result, their demographic information is not available. 
calling. If you look at me a certain type of way, I'm calling. If you cough a certain type of way, bitch, I'm calling." What distinguished this small group from the majority of study participants seemed to be their connections to the police through social networks such as family, friends, or co-workers. Quinn, a 21-year-old transgender woman whose mother worked with Newark police, stated, "I feel comfortable ... So if something happens, I call them." However, these participants still demonstrated awareness of reporting barriers and problems with the police. Brandy, an 18-year-old transgender woman, called the police her "girlfriends". But she still displayed reservations, stating, "I will press charges, I will file a restraining order or whatever, but to call the cops if you need help? No." Lamar agreed, noting, "[the police] would take their time ... depending on how deep in Newark or what ward you're in."

Compared with their hypothetical discussions, around a third of the sample (37\%) reported having actually summoned the police. Strikingly, this included only one medical emergency, despite a number of participants stating they would seek out the police in this situation. Roughly half of the calls made were for violent incidents, including IPV, robbery, and other physical altercations (50\%). Approximately a fifth of calls were for serious harassment and/or threats (19\%), while roughly a quarter of these incidents were for general assistance $(23 \%)$, such as car accidents, being stranded in a vehicle, and requesting a police escort ${ }^{8}$. Notably, study participants described nine incidents in which they called the police for IPV; all but two were made by women (six cisgender women and two transgender women, respectively). The outcome of nearly all of these calls $(84 \%)$ were negative, with participants noting police did not respond in a timely manner, were discourteous, operated in homophobic or heterosexist ways, engaged in harassment, or did not successfully resolve the incident. However, the majority of these police-citizen interactions (64\%) were not specifically related to participants' identities as SOGI minorities (i.e., they were not victimized in the context of IPV with a same-sex partner or due to anti-LGBTQ bias and/or their SOGI status was not highlighted by the responding officer). Similar to reported IPV incidents, police-citizen encounters in which a participant's LGBTQ identity was a focal point of the interaction ${ }^{9}(N=15)$ were also more likely to be encountered by female cisgender $(N=4)$ and transgender women $(N=5)$ relative to cisgender men $(N=2)$ and transgender male participants $(N=1)$.

Some participants described situations that were roundly dismissed as trivial and by extension, unworthy of reporting, such as verbal street harassment that did not involve express threats or more serious forms of harassment (e.g., harassment perpetrated by a group). Micah, a 21-year-old gay man, said non-violent verbal harassment did not warrant calling the police, as "you can ignore it until they decide to put [their] hands on you. That's where you draw the line." However, some LGBTQ people-particularly transgender women and men-may not equate verbal harassment with "violence," as this type of victimization can become normalized and perfunctory through regular exposure to it (Jauk 2013, p. 812). Participants also identified several other types of incidents that they did not consider serious enough to warrant police involvement, including noise complaints, car accidents or disabled vehicles, shoplifting, the retrieval of property, and requesting police escorts.

Strikingly, when asked who they would initially contact in the event that they were the victim of an anti-LGBTQ bias crime (see Appendix A), nearly all of the participants who answered this question $(N=56)$ indicated the police would not be their first choice and that they would prefer to reach out to others instead (91\%). Of the participants who indicated they would not reach out to the police $(N=51)$, they most often stated they would seek assistance from their social networks via their family (47\%) or friends (22\%). Less commonly, participants disclosed they would engage in self-help by fighting back $(12 \%)$, while others $(19 \%)$ gave miscellaneous responses, such as "it depends," "someone else," or "not the police." When they discussed their decisions, participants were emphatic

In five cases, study participants did not provide details about the circumstances in which they called the police.

9 Three of these incidents involved participants whose demographic information is not known due to their participation in the pilot focus groups. 
about their preference to seek help from informal sources over the police. Khalilah, an 18-year-old lesbian, pointedly asserted her preference to contact her friends, as she felt they "... could get shit done better than the police could." Despite their vulnerability as prospective bias crime victims as LGBTQ people of color (e.g., NCVAP 2017a; Meyer 2010), it is telling that participants would feel more comfortable operating through informal channels versus risking an uncomfortable or unhelpful response from the police.

\subsection{Rationales for Avoiding the Police}

Participants were also asked to articulate the reasons behind their decision to avoid contacting the police. Broadly speaking, these rationales were grouped into two distinct categories: (1) generalized concerns about the police not specifically linked to participants' LGBTQ identities, and (2) LGBTQ-related concerns directly tied to participants' status as sexual and/or gender minorities. Generalized concerns reflected themes commonly observed in urban contexts (see Brunson and Gau 2014) including doubts about the efficacy and helpfulness of the police, prior negative contacts with the police, and a fear of negative consequences arising from police interactions. Concerns that were specifically and overtly anchored in participants' identities as LGBTQ people related to fears of insensitive or discriminatory treatment based on their SOGI status, feelings that the police would not be helpful or take their complaint seriously in situations where sexuality and/or gender identity was integral (e.g., bias crimes and IPV), and negative prior contacts with the police related to their SOGI identity, including derogatory, harassing, or otherwise homophobic treatment. Trans participants were particularly fearful of discrimination and their identities were especially salient in their consideration of avoiding the police.

\subsubsection{The Police Are Not Helpful in Urban Communities}

Consistent with prior work about the perceived effectiveness of the police in urban, economically depressed communities (e.g., Brunson and Miller 2006), each focus group contained participants who expressed skepticism and mistrust towards police. Many underscored slow response times and believed that even if the police did respond, they either could not or would not be of effective assistance. The belief that police would not respond to calls for assistance in a timely manner cemented participants' perceptions that they were uncaring. As a result, participants perceived contacting the police as an exercise in futility. Some drew on their beliefs about police efficacy, while others drew directly on past negative experiences.

Brian, a 22-year-old gay man, said the police "take forever to come because they really don't give two shits because you're in the hood where they really don't care what you're doing." According to Eli, a 22-year-old $\operatorname{man}^{10}$, "The police need to be more efficient.... [it takes] mad long for the cops to come." Sierra, a 21-year-old transgender woman, bitterly recalled calling the police during a domestic dispute in which she was "thinking I'm in danger and stuff." She said the police took over $90 \mathrm{~min}$ to respond and as a result, she "would rather die" than call them in the future. Similarly, Alexis, a 19-year-old gay man and Vivan, a 20-year-old lesbian, elaborated on their disillusionment with the police as a result of slow response times:

Vivan: My mom and her ex-boyfriend was fighting and it got to the point where somebody was bleeding really bad ... So we called the cops ... and it took them, like, at least forty minutes to get to the damn thing.

Alexis: That's why I don't waste my ... time even calling them. I just do what I got to do.

Vivan: I always think ... what if, what if the guy would've beat my mother to the point where it wasn't no coming back? ... I have no faith in law enforcement.

10 Eli responded to the demographic questionnaire by writing in he is "not very into label very me (sic)." 
Other facets of participants' belief that the police were unconcerned with their welfare related to police procedures. Participants said that even if the police did respond in a timely manner, they still would not be of help due to the flawed process of reporting crimes and the potential ineffectiveness of police investigations. An exchange between Loretta, an 18-year-old trans woman, and Cedric, a 21-year-old gay man, illustrated their shared belief that calling the police would be fruitless. Loretta explained, "I'm not going to call the cops because the cops won't-what are they going to do? ... They going to ask me to come to the law station, fill out a report, then they'll get back to you." In response, Cedric added, "And then nothing is going to get done." Similarly, Jace, an 18-year-old lesbian, posited, "I probably wouldn't even call [the police]. Because what's the point? ... They like, really don't help you." Veronica (a 23-year-old transgender woman), Brandy, Lyndsey, and Sierra were also doubtful that the police would be able to track down a perpetrator:

Ingrid: I mean, they come, but they come slow. By the time they get down there I been handle it. Honey, dust it off, and washed my hands and-

Brandy: Especially when you get robbed and they be like, "Alright, file a police report." Girl, I'm not doing all that.

Lyndsey: Yeah, what the fuck is that?

Sierra: I don't even remember how they look like.

Brandy: They are not going to find them ... The only thing I may be able to tell them is he was tall, dreads, light skin, cute. And [the officer] be like, "Okay".

Thus, participants felt that bureaucratic inconveniences, such as filing reports, combined with the likelihood that the police could or would be able to identify unidentified perpetrators, meant that summoning the police would be pointless.

\subsubsection{The Police Are Not Helpful for LGBTQ Citizens in Urban Communities}

In addition to the concerns outlined above, participants also expressed a range of concerns specifically centered on their SOGI identity. For instance, some participants felt the police would not take their complaint seriously due to their LGBTQ identity and would treat them differently than heterosexual and cisgender victims. Xander, a 21-year-old gay man, noted, "I'll call the cops-I've seen gay people and the cops dealing with them, they take it as a joke, laughing at them, making fun of them. And like, it's serious ... [T] hey need to respect us." Lashawn, a lesbian in her twenties, expressed concerns that the police would behave in an outright derisive manner towards LGBTQ victims:

If it's a gay situation, they, when they get there, they're going to crack jokes, they're going to have their own personal biases towards you and they're not even going to hide it. They're not going to wait until they get in the cop car to make these remarks. No, they're going to pull up to the scene, snicker when they see that, like, two men or two women who are romantically involved, they'll start snickering like, "We're here for this?" You can see, like, their whole ... disposition just changes and their attitude towards helping you and asking you questions.

Similarly, Jaden, a 52-year-old lesbian, who called herself an A.G. ${ }^{11}$, described a situation in which she called the police during a violent incident involving her relative and their same-sex partner. Six officers responded to Jaden's call, two of whom she described as "part of [the LGBTQ] community." She said these two officers "took [the incident] very serious," but was irritated by the response of the four heterosexual officers: "When they arrived ... the four thought it was a joke, you know ... . Like, I had to correct those four officers. Like ... 'This is real. This is serious.'" Billie, a 51-year-old lesbian, offered, "I think the consequences ... for us as LBGT folk are greater ... . [W]e would hesitate to call the police because ... they're not supportive."

11 Some women participants used this term as shorthand for "aggressive girl," referring to lesbians with a particularly masculine gender presentation. 
Lauren, an outreach worker, recalled that in the course of her professional role working with LGBTQ youth:

We've had several incidents ... where some of the kids have been attacked by people ... in the community ... but they choose not to say anything because we feel like the cops are not going to do anything ... . They'll probably be like, "Oh, this is just a faggot. We don't care." And that's exactly how they approach it.

Lashawn witnessed an incident that confirmed these expectations:

It was two guys who were romantically involved. They were in a relationship and ... they were getting ready to like, have a little altercation and somebody else jumped in so they ended up, like, beating the other guy. So then they called the cops, and the cops, you know, at first he just thought it was two, like, straight guys going at it but then when they saw that it was two gay guys who, like, beat this other guy up, it was like, "You let these two fags beat you up? We shouldn't even take this report." Like making a joke of it.

With respect to same-sex romantic relationships, Latasha pointed out the police "don't take same-sex relationships the same as um, straight ... . Like, when we argue or fight ... they just look at it and be like, 'Oh, well, y'all need to go separate.'” Thus, LGBTQ IPV victims may hold perceptions the police would engage in differential treatment regarding their victimization by behaving in a cavalier, uncaring manner.

In a similar vein, some participants expressed a desire for the police to treat them with basic humanity in order to affirm the dignity of LGBTQ people and take their victimization seriously. Kobe, a 24-year-old gay man, said Newark's LGBTQ community desires "to be seen as just being people and ... human beings." Arleen also wished officers would treat her as "an individual" rather than "this, you know, gay kid." Furthermore, Latasha requested that officers not speak to LGBTQ citizens like "we not a piece of trash," while Deiondra asserted that officers should not "talk to us like animals." Charlene, a 50-year-old trans woman, elaborated:

They don't perceive us as people, human beings, mammals of the earth, normal, you know, every day people going through life. They don't even see that ... . All gay men, trans women: they're promiscuous, they're hookers. Uh, everything but human beings.

Many participants described the police as distant and uncaring, leading to perceptions that they are not a reliable source of assistance. Brayton stated, "a lot of people feel uncomfortable going to the police because they are gay" and believe they will not be treated "in a respectful manner." Andy, a 24-year-old lesbian, said "I can't call the police for everything. I can't call the police for most things," and noted she preferred to handle incidents on her own. Elaborating, Billie, a 51-year-old lesbian, said the police "don't care" about the LGBTQ community and surmised that multiple stereotypes seep into how the police interpret complaints from LGBTQ citizens, deterring them from reporting their victimization:

The police officers generally are not going to approach the situation in a neutral way. They're approaching the situation with all these layers of stereotypes that they have around being brown people, being people of other than heterosexual experience. And so, I don't think that ... police officers are a safe bet for us.

Taken together, such apprehensions and experiences dissuade many LGBTQ victims from reporting their victimization to the police. Indeed, prior research finds that SOGI minority victims who anticipate biased treatment by police may feel discouraged from reporting (Briones-Robinson et al. 2016).

\subsubsection{The Distinct Experiences of Trans and Gender Nonconforming Participants}

Participants who identified as trans or as outside of binary gender presentations experienced or anticipated mistreatment due to stereotypes and misgendering. Erica, a 28year-old trans woman, stated, "[the police] don't respect the transgender community .... . 
Whether you're wrong, or indifferent, they're always gonna downplay you because you're transgender." Jace, an 18-year-old lesbian, offered, "if I call the cops ... and they hear that I'm a female but when they come I'm dressed like a guy ... everything changes ... . [They would think], 'she's a man, so why does she call me?'" Octavia, a 56-year-old lesbian, recounted that police repeatedly called her "sir," adding, "'You have my driver's license in your hand. You don't know I'm a woman? Did you look at it?'” Dion, a 43-year-old lesbian, described similar difficulties and noted, "If I take my cap off or I take my hat off, I don't have that problem. None at all." Consequently, Charlene, a 50-year-old transgender woman, surmised, "I don't like the way [the police] treat the trans community." A few trans participants also mentioned fears of being labeled as sex workers. Ayana reported being called "a prostitute" by an officer while walking in a public space. Loretta described an incident in which police attempted to arrest her for sex work, explaining, "One day, you know, I was just (pause) parading around (laughs) and they tried to get me." Loretta added:

The Newark cops, it's like, the Newark cops have something against us transgenders. They have something against us .... . They be chasing us, child. (laughs). ... They don't like us, so that's why people don't really, like, call them for help. We really won't, like, it has to be like, hell on ice for us to have to really like, get up and go to the police station because they won't help us.

Cisgender participants also noted the difficulties faced by the trans community. Alexis, a 19-year-old gay man, said, "people get up in drags and walk downtown, then they're accused for prostituting and voguing ${ }^{12 "}$. During an exchange with Loretta, Lamar, a 25-year-old gay man, declared, "when Loretta and the other transgender girls out working, um, the police take aggressive force because they don't know how to handle a transgendered woman." Furthermore, Brian, a 22-year-old gay man, disclosed, "And if you are transgender or you ... full-term walk as a woman, and you don't look like a woman, you get attacked by anybody. You get harassed by cops." Thus, it appeared transgender and gender nonconforming participants had especially adverse experiences with insensitive or antagonistic officer behaviors, leading to a shared perception that officers are not safe to interact with, even when needed.

\subsection{Consequences of Seeking Help from Police}

Participants mentioned a range of potential consequences from contacting the police for assistance, including the possibility of negative police interactions (e.g., harassment or arrests), as well as reprisals from the perpetrator(s) implicated, or being labeled a snitch. These concerns were consistent with common misgivings about police contacts among citizens in urban settings. Other themes were directly tied to participants' LGBTQ identities, as they were concerned they would experience or actually had experienced homophobic or transphobic police behaviors.

\section{General Consequences}

Some participants were fearful that contacting the police for help would result in their own arrest and/or that force might be enacted against them. Brian, a 22-year-old gay man, stated, "you'll be trying to call somebody for help and they wind up being the type to get you in trouble and lie on you." Blake, a 19-year-old gay man, had such an experience. He noted, "I called the cops because I was getting attacked and I got locked up." He explained, "even if you never had an experience with [the police] ... you're going to think they going to do some bullshit to you." Tristan, a 24-year-old gay man, recalled, "I don't want to call the cops because they quick to put anybody in handcuffs. Even persons who ain't got nothing to do with the situation." Kobe, a 24-year-old gay man, added that he felt police are "too aggressive." He described having been "severely, like, patted down, thrown around, and stuff like that" as well as being "cuffed up." Tristan, Kobe, and Micah (a 21-

12 The term "voguing" refers to "a form of stylized dance that was developed by LGBTQ people of color in New York and introduced to mainstream culture by Madonna's 1990 hit 'Vogue'" (Matthes and Salzman 2019, para. 5). 
year-old gay man) each separately discussed concerns about forceful treatment, including the potential for such encounters to culminate in an arrest, even when summoning officers for assistance. According to Micah, "a lot of the community has ... their issues with the cops. Their [outstanding] warrants and et cetera ... . It might not have been the cause of the situation, but they don't want [the police] knowing they have this in their background." Micah's discussion highlights that fear of arrest for unrelated activities can deter LGBTQ community members from relying on the police.

Other participants relayed concerns about retribution associated with perceived snitching from the perpetrator, their friends, or other neighborhood residents. Spencer, a 19-yearold gay man, noted that even if he were to reach out to the police and identify a perpetrator, there could be harmful—even deadly—ramifications for doing so:

If I get Dayday from down the hill locked up, Dayday from down the hill only get locked up for thirty days. He could've beat me, he could've lit me on fire, but in thirty days Dayday will be outside waiting for me and beating me up again ... . Y'all just going to keep him in there and Lord knows, he probably ... already been to jail fifty times so he don't really care to go back because he know that if he hit me it doesn't matter, like he's going to go back and he's going to get out .... Nobody is going to stop harassing you because you called the police. Because Dayday also know Tayday from around the corner (laughs).... And Tayday from around the corner is just as ignorant as him.

Additionally, Lyndsey, a 20-year-old trans woman, explained, "The cops just make it even worse ... Once the cops go, you still live in that household." Kass, a 24-year-old trans woman, affirmed, "if they see you as a snitch, they're going to beat you up. They're going to, you know, jump you ... If you call the cops and you live in the 'hood, you could get shot for calling the cops .... . Real fast."

\subsection{The Impact of LGBTQ Identities on Interactions with Police}

Some participants described misgivings and experiences of negative impacts from summoning the police as an LGBTQ person. Participants' fears and experiences related to biased treatment rooted in heterosexism in three areas: police misconduct stemming from homophobia and/or transphobia, the treatment of IPV among LGBTQ couples, and the disparate treatment of the transgender and gender nonconforming community.

Participants described overtly homophobic instances of police misconduct with officers, including the use of homophobic slurs and other derogatory language, sexual harassment and sexual propositioning, and physical abuse. Sometimes these incidents occurred outside of calls for service, when study participants were navigating the streets of Newark. Such encounters are troubling, resulting in the collective assessment that calling the police is an unsafe gamble, at best (Brunson 2007). The anticipation of potential homophobic misconduct means contacting the police can be an undesirable prospect, at best.

With respect to police misconduct, participants most frequently described homophobic verbal harassment. Latasha recalled a time when Ayana, a transgender woman and fellow participant, was called a "faggot" repeatedly by police officers, while Brayton witnessed officers refer to citizens as "fag boys." Ayana also reported the police barred her from using the women's restroom in a public space after telling her, "well, you're a guy." Aaron, a gay man in his late fifties, recalled that officers called his co-worker a "McGreevey," referencing former New Jersey Governor Jim McGreevey, a gay man. Additionally, Vivan, a 20-year-old lesbian, was asked by an officer about her sexual orientation, and the officer responded, "'Oh, you too pretty to be a lesbian.'" While "up in drags," Alexis was stopped and told by an officer, "'Oh, if you was a girl, we would have sex." Harmony also described an incident in which she was harassed by officers:

The cop that pulled me over, it was like, well, "Why are you out here? You need to be in the house." You know, um, "only people that's out is your kind." I'm like, "Well, what do you mean my kind? Like, specify that." So, he's like, "Well, you know what I mean. Y'all he-she's," quote unquote. 
Other participants described officers engaging in misconduct when arresting them. Shakia, a 23-year-old transgender woman, described that when officers arrested her and two others, they "just started like, stomping us," and one of the officers referred to her as "a fucking' fag" during the assault. Erica, a 28-year-old trans woman, recalled when a friend "turnt a date" and the incident devolved into a physical fight that led to police intervention. While being interviewed, Erica said the detective "literally snatched my hair" and also verbally harassed her, stating, "you're a fucking male and this and this, what were you doing, prostituting?" Dana, an 18-year-old lesbian, described an officer arresting her saying, "'Yo, this girl look just like a boy .... She's going to make all the girls go crazy in [jail].'”

Some participants also recalled involuntary contacts with the police steeped in transphobic and/or homophobic mistreatment that operated through misgendering. In one such encounter, Wanda, a 20-year-old lesbian who identified as masculine, described an incident where she was stopped and subsequently searched by male officers:

They're like, "Get on the wall," and I'm talking to them ... "Last time I checked, y'all [male officers] can't check me." He's like, "Oh, why can't we check you?" "I have breasts and a vagina. Just because I have on baggy clothes that don't mean that I'm a guy," but they still checked me and they didn't care ... . I was trying to be funny. I was like, "I'm on my period, so be careful." So, he was like, "Oh, you're going to get blood on me or something?" And then he really thought I was playing that I was a female until ... I took my zipper down and everything because they was like, "Take everything off, like, your, your coat or whatever." And I'm like, "I'm a female. Like, I don't have to lie to you."

Finally, several outreach workers experienced police harassment when attempting to do outreach activities (see also Mallory et al. 2015). Emma, a transgender woman, described handing out condoms wearing an official ID from her agency. An officer approached her, stating, "'You know you're soliciting sex, right'"? Similarly, Brayton noted "we had five police cars come, they took pictures of us, they took our names ... like we were soliciting and everything." Charlene, a 50-year-old trans woman, echoed their experiences, as she recalled, "like sometimes residents would call the cops and they would describe my vehicle and say, 'Well this vehicle is parked outside my house and they're soliciting.'" Aaron attempted to combat this problem for his organization by applying for a permit to perform outreach work in spaces where workers were being regularly accosted by police. Aaron stated, "we actually try to ... follow the letter of the law .... They tell us we needed a permit ... to do what we do." However, he was met with significant resistance during the process. After being turned away twice, Aaron exasperatedly declared, "so we have been given the run-around about what we're trying to do."

Concerning IPV incidents, only women study participants discussed the negative impacts of police responses. These experiences were generally negatively tinged by officers' reliance on heteronormative stereotypes regarding typical IPV incidents featuring cisgender, heterosexual couples, where femininity is equated with victimization and masculinity with perpetration (see Guadalupe-Diaz and Jasinski 2017). Officers seemed to expect stereotypical gender dynamics to occur, even in the context of same-sex couples (see Hassouneh and Glass 2008). These assumptions produced negative outcomes for masculine-presenting women, as they were identified as the initiator of IPV incidents based on their gender presentation. As one example of this dynamic, Bernice, a 30-year-old lesbian, felt she was targeted by the police due to her masculine appearance after her feminine partner battered her:

I called the police, for my safety, and at this point I had, like, a black eye or two and, like, a missing tooth and everything. And when the police came, they actually just went straight to me and I ended up going to jail without even having asked questions at all and, like ... they automatically thought that I was a man so the, the officers that were there, they were male officers that searched me for everything and that, um, patted me down and that actually arrested me. But then even once they realized I was not a male, I was still the person that went to jail. 
In other instances of IPV, the couple was simply threatened with dual arrest due to the inability of officers to correctly determine the identity of the perpetrator. This tendency is consistent with a recent analysis that revealed disparate outcomes for IPV events between same-sex romantic partners, as officers were significantly more likely to enact dual arrests relative to IPV between heterosexual couples (Hirschel and McCormack 2020). In one such instance, Andy, a 24-year-old lesbian, called the police after being choked by her partner. As both women were masculine-presenting, the officer's identification of the aggressor appeared to rely on stereotypes related to typical gender-based victim and perpetrator patterns during IPV incidents. Unable to identify the perpetrator, the officer threatened to simply arrest both women:

Like, they didn't know what to do. So it's kind of like they were rolling up on a situation of, like, two gay guys and they're just like, "Alright, y'all both going to jail. Y'all can't figure this out, we'll send you both to jail." Because by the time they got there ... we were calmed down .... They don't know who the aggressor is, like, they don't want to ask, you know what I'm saying? Because they're going up and they're just making assumptions on your appearance, you know? ... Like, so, it was something like, it was my word against hers and it was, like, how I was presenting versus how she was presenting, you know what I'm saying?

With respect to the trans community and their experiences with the police, some trans women feared their identity would significantly and negatively impact these interactions. Several described the police as insensitive and/or disrespectful due to their status as trans women. Yvette, a 33-year-old trans woman, stated the police "harass rather than help." Transgender participants were concerned that responding officers would, instead of responding to the incident itself, focus on their transgender status, resulting in a problematic interaction rooted in prejudice and stereotypes against the transgender community. An exchange between Shakia, Charlene, and Erica, all trans women, illustrated these perceptions:

Shakia: You could've been the one calling them and they'll make it about you-

Charlene: You, mmhmm.

Erica: Mmhmm.

Shakia: - and your transition. What does that have to do with me calling you? I called you to help me.

Furthermore, Jenine, a 32-year-old trans woman, was physically attacked by a group of youths, but described the police as slow to respond. When the police did arrive, they focused on her status as a transgender woman: "Once they got there, they were like, 'oh, um, do you think it was because you're gay?' That was the first question. And I'm like, 'what makes you think I'm gay? ... I'm a woman.'” As a consequence, Jenine said, "next time that somebody tries to bash me, I'm gonna bash their head open and then I'm gonna call you ... . You never helped me before, this is what you get now."

\section{Discussion}

In an attempt to extend the literature in this area, the current study examined the range of concerns, fears, and negative police experiences that may impact and suppress reporting behaviors among LGBTQ people. By focusing on when and why participants would seek help from the police, this study sought to build upon existing scholarship that has consistently suggested a concentration of negative experiences with and perceptions of law enforcement among the LGBTQ community (Dario et al. 2019; Hodge and Sexton 2018; Satuluri and Nadal 2018; Owen et al. 2018; Nadal et al. 2015; Woods et al. 2013; Wolff and Cokely 2007). In doing so, this study embraced an intersectional perspective (Crenshaw 1991a, 1991b) by specifically targeting the experiences of LGBTQ participants of color. Not only are racial and ethnic minorities overrepresented within the LGBTQ community (Deschamps and Singer 2017), but relative to their white counterparts, LGBTQ 
people of color are also likely disproportionately subjected to inappropriate treatment by the police (Amnesty International USA 2005; Center for American Progress 2016; James et al. 2016; Woods et al. 2013) and experience overrepresentation in the criminal justice system as offenders (Meyer et al. 2017) despite their vulnerability as prospective victims of crime (Dunbar 2006; Kuehnle and Sullivan 2001; NCVAP 2018; Meyer 2010).

Overall, the patterns observed amongst this sample are consistent with and extend the burgeoning literature related to policing of LGBTQ people and the various problems LGBTQ citizens might encounter-or anticipate encountering - when interacting with the police to seek their assistance. Participants expressed sentiments that the police should be avoided except under select circumstances (if they are to be contacted at all), held a generally low opinion of the police, amassed mostly negative encounters with the police, and recounted instances of misconduct and harassment from officers. Their reasons for avoiding the police were both rooted in more generalized concerns observed in urban, over-policed environments as well as rationales specifically linked to their identities as SOGI minorities.

When asked when they would hypothetically contact the police, one-third of responding participants indicated they would not reach out to the police regardless of the situation, while two-thirds expressed that they would only do so for especially serious incidents, such as violent encounters, serious harassment, and medical emergencies, signaling a pronounced hesitation to seek help from the police barring potentially life-threatening events. This slightly departed from the situations in which participants actually did report calling the police, which were more varied and only included one medical emergency. Most participants who voluntarily contacted the police were met with a poor experience, meaning that the police were untimely, discourteous, ineffective, and/or engaged in harassment or other problematic behaviors. The importance of the tone of police-citizen interactions cannot be understated, as an accumulation of negative experiences with the police may potentially suppress reporting behaviors (Carr et al. 2007; Miles-Johnson 2013b; Xie et al. 2007) while positive interactions may improve citizens' perceptions of the police and lead to increased cooperation (Peyton et al. 2019). Even the viewpoints of those who have not directly interacted with the police can be altered by recounted vicarious negative experiences relayed through their respective social networks (Rosenbaum et al. 2005), ultimately producing a shared negative view of the police (Brunson 2007) that may discourage them from reporting crimes.

Some of participants' rationales for police avoidance were grounded in general concerns commonly broached by citizens regarding their lack of confidence in the general performance and effectiveness of the police that has been noted in studies of racial and ethnic minorities (e.g., Weitzer and Tuch 2005). Participants relayed frustrations with poor response times and other barriers to service, such as the perceived difficulties associated with reporting crimes, resulting in the perception that calling the police was largely pointless. Furthermore, participants believed that even if the police did respond in a timely manner, they would not be particularly effective in their assistance, might be discourteous, or may engage in more serious forms of misconduct. Participants also relayed concerns about the potential consequences of contacting the police based both on previous negative experiences and/or expectations that the police would behave ineffectively or even aggressively. Consistent with work that has noted a concentration of police harassment and misconduct in economically depressed communities with a concentration of people of color (e.g., Brunson and Miller 2006; Rengifo and Fratello 2015), some participants feared these same dynamics might be present during their own interactions with the police, while others directly experienced these consequences.

Other themes outlined by participants were directly related to their SOGI status, including lack of sensitivity among the police when responding to calls about specific LGBTQ issues, such as bias-related victimizations and IPV, and/or situations in which participants' LGBTQ identities were highlighted at some point during the interaction (e.g., officers engaging in misgendering, referring to a participant's SOGI status, or making 
assumptions about the dynamics of same-sex romantic relationships). Some participants felt the police would be homophobic or transphobic in their disposition towards SOGI minorities, with some participants drawing from direct experiences that lent credence to their misgivings. These sentiments are consistent with the literature that has studied the nature of police interactions with LGBTQ citizens and have detected a troubling level of insensitivity, harassment (Hodge and Sexton 2018; NCVAP 2018; Wolff and Cokely 2007), and anticipated harassment (Briones-Robinson et al. 2016). Further, in line with previous work with transgender people that has revealed an especially low regard for the police and frequent exposure to police misconduct (Grant et al. 2011; Guadalupe-Diaz 2016; Miles-Johnson 2016; Miles-Johnson 2020; Stotzer 2014b; Woods et al. 2013), transgender participants were concerned their gender identity would become the central focus of their encounters with the police and produce a poor outcome.

Unfortunately, some participants also felt the police would treat their complaints as insignificant and would not take them seriously, as has been mirrored in prior work with LGBTQ populations and their interactions with the police (Bernstein and Kostelac 2002; Herek et al. 2002; NCVAP 2017a, 2017b; Wolff and Cokely 2007). A sensitive response from the police is especially crucial for offenses that are underreported and tied to feelings of shame, including IPV and sexual assault, as LGBTQ citizens who anticipate discriminatory behaviors on the part of the police may be less likely to report their victimization (BrionesRobinson et al. 2016) despite an increased risk of sexual assault (Rothman et al. 2011), the presence of IPV within the LGBTQ community (e.g., Guadalupe-Diaz 2016; Messinger 2017), and the dangers posed by anti-LGBTQ bias-related crimes interlaced with violence (e.g., Herek 2009). In particular, the police need be perceived as an approachable, trustworthy, and safe source of assistance for anti-LGBTQ bias crimes due to their inherent stigma and reduced likelihood of disclosure to the police (Herek 1989; Pezella et al. 2019).

Overall, the patterns observed among the data should be viewed from the vantage point of intersectionality, as under its assumptions, LGBTQ individuals of color will have particularly adverse interactions with the police due to multiple identities traditionally associated with societal marginalization (Burgess-Proctor 2006; Crenshaw 1991a; Crenshaw 1991b; Gaynor and Bassett 2020). This study offers a unique look at these dynamics due to the composition of its sample, which is primarily comprised of people of color. It also extends the literature concerning the role of interlocking identities and their potential to generate negative ramifications during interactions with the police (e.g., Panfil 2018). Analogous to other work that has examined intersectionality's effects upon multiplymarginalized LGBTQ people (Woods et al. 2013; Robinson 2020), participants offered legitimate concerns about interacting with the police due to distrust and a desire to avoid them. Participants' experiences can also be viewed as an extension of the racial, ethnic, and class-based characteristics present in Newark, as it is an urban environment featuring elevated police surveillance experienced by people of color in similar settings (e.g., Brunson and Miller 2006). The role of intersectionality is also illustrated by transgender and gender nonconforming participants, as they described being subjected — or feared being subjectedto stereotypes espoused by officers; given the existing work surrounding transgender women of color and their negative police-citizen interactions (e.g., Graham 2014; James et al. 2016; Mallory et al. 2015; Woods et al. 2013), these concerns are not surprising. Consistent with other work that has pointed to possible underreporting among LGBTQ people of color (Guadalupe-Diaz 2016; Kuehnle and Sullivan 2001), many participants indicated they would not seek police assistance in the event of anti-LGBTQ bias victimization; this is especially concerning in light of elevated victimization rates experienced by SOGI minorities who are also people of color (Dunbar 2006; Meyer 2010; NCVAP 2017a, 2017b). Taken together, these results highlight the importance of increasing the comfort of those with intersectional identities during encounters with the police.

Indeed, it is apparent increased cultural competency and sensitivity among law enforcement is sorely needed (see Dario et al. 2019; Hodge and Sexton 2018; Satuluri and Nadal 2018; Owen et al. 2018; Nadal et al. 2015) in Newark and as well as other similar 
locales that aim to improve interactions between the LGBTQ community and the police. Newark represents a particularly suitable environment to examine these issues. Alongside "anecdotal" accounts of police mistreatment towards LGBTQ citizens in Newark (United States v. City of Newark 2016, p. 48), only two other cities-Baltimore and New Orleans-have verified systematic anti-LGBTQ bias through Consent Decrees (DOJ 2017; United States v. Police of Baltimore City 2017; United States v. City of New Orleans 2013). Like Newark, Baltimore and New Orleans are urban, metropolitan areas with above-average crime and poverty rates that are also comprised mostly of people of color (United States Census Bureau 2017). As a result, the findings of this study may be applicable to similar urban contexts that have historically fostered a troubled relationship with the police. Thus, it can provide insights about how to better police LGBTQ communities in these locales. In the aftermath of Newark's Consent Decree with the Department of Justice (Newark Department of Public Safety 2018), it has taken early steps to attempt to improve its treatment of LGBTQ citizens. For instance, the NPD recently directed officers to "not question [a] person's gender identity" and separate transgender people from the general population while they are in custody (Nelson 2019a, para. 1). Unfortunately, however, the variety of reforms included in the NPD's Consent Decree to address Newark's policing practices does not formally include the LGBTQ community and are still a work in progress (Nelson 2019b).

As noted by Dwyer (2019), it can be difficult to ascertain the best way to improve the competency of the police with regard to LGBTQ issues and people through targeted training. In the current study, participants offered a range of suggestions ${ }^{13}$ to better assist Newark's LGBTQ community through four overarching areas that can be used to guide future research and policy-making; on a positive note, some of these suggestions are currently being undertaken by the city of Newark presently, lending credence to the need to address these issues. First, participants requested mandatory, department-wide training to promote increased cultural competence, sensitivity, and professionalism towards the LGBTQ community; ideally, this would include educating officers about the wide spectrum of sexual orientations, gender presentations, and gender identities present in the LGBTQ community, the proper usage of LGBTQ-related terminology and pronouns, and guidance regarding appropriate responses to LGBTQ victims of IPV and bias-related crimes. Second, participants mentioned a need to appoint trained NPD officers as liaisons that serve LGBTQ residents and crime victims. Third, participants requested a more prominent and visible presence of "out" LGBTQ NPD officers. Finally, participants also expressed a desire for the police to immerse themselves in the Newark's LGBTQ community through participation in Newark's LGBTQ-related events (e.g., Newark's annual pride festival), hosting events such as meet-and-greets, and demonstrating their support of local LGBTQ-oriented grass roots organizations and community leaders. To repair the divide that has formed between the police and LGBTQ citizens, establishing trust and feelings of comfort is crucial in order to increase reporting rates, and ultimately, better protect and serve this vibrant and important segment of the population.

Funding: This research was funded by The Rutgers-Newark School of Criminal Justice Dean's Research Grant.

Institutional Review Board Statement: This study was conducted according to the guidelines of the Declaration of Helsinki, and approved by the Institutional Review Board of Rutgers UniversityNewark (Protocol \#12-520-M approved on 25 February 2013).

Informed Consent Statement: Informed consent was obtained from all participants involved in this study.

Data Availability Statement: The data are not publicly available because of its extreme sensitivity. Due to the specific and detailed qualitative narratives provided by participants—some of whom hold

13 As these responses were numerous and varied, they will be systematically examined through a separate analysis. 
social significance through their open involvement Newark's LGBTQ community-it is possible that they may be publicly identified through this data and may face repercussions as a result.

Acknowledgments: First and foremost, I would like to extend my deep gratitude to Jody Miller for her assistance with this manuscript as well as her ongoing dedication and support of my work. I would also like to thank Valerio Baćak, Jasmine Silver, Randall Shelden, and the anonymous referees for their valuable guidance in revising this manuscript. Furthermore, I am grateful to both Maren Greathouse and Meda Barker for their crucial roles in facilitating this project as well as the various stakeholders and LGBTQ community centers that were key in accessing participants and were willing to give me space to do this important work. Finally, I would like to extend my sincere and heartfelt appreciation to the all of the participants who were willing to take part in this study, as this work simply would not have been possible without their trust and willingness to share their stories.

Conflicts of Interest: The author declares no conflict of interest.

\section{Appendix A. Complete Focus Group Interview Guide}

1. Can you tell me a bit about the LGBTQ community in Newark?

2. How open do you feel you can be about your sexual orientation/gender identity in your neighborhood?

3. Under what circumstances would you ask the Newark police for help?

a. Under what circumstances would you not ask the Newark police for help?

4. If you were the victim of a bias crime (e.g., verbal harassment or intimidation, destruction of property, or physical assault, etc., based on your sexual orientation/gender identity), who would you contact? How comfortable would you feel going to the police in this situation?

5. Based on what you've seen and heard, if someone is a member of the LGBTQ community here in Newark, does it usually affect the way they are treated by the police?

b. If yes, why?

c. If no, why not?

6. Have you had any experiences, good or bad, with the Newark police? What happened and what was your experience?

7. For those of you who haven't had any experiences with the Newark Police, are you ever concerned about how they might treat you? Can you tell me about why that's the case?

8. How do you think police officers could improve their relationship with the LGBTQ community in Newark? What kinds of things would they need to change?

\section{References}

Avdija, Avdi. 2010. The role of police behavior in prediciting citizens' attitudes toward the police. Applied Psychology in Criminal Justice 6: 76-90.

Ambrose, Anthony. 2019. Department of Public Safety Memorandum: Implementation of General Order 19-03 Re: LGBTQ Community E Police Interactions. Newark: Police Division.

Amnesty International USA. 2005. Stonewalled: Police Abuse and Misconduct Against Lesbian, Gay, Bisexual and Trans* People in the U.S.. New York: Amnesty International, Available online: https:/ / www.amnesty.org/ (accessed on 1 January 2021).

Aulivola, Michelle. 2004. Outing domestic violence: Affording appropriate protection to gay and lesbian victims. Family Court Review 42: 162-77. [CrossRef]

Bernstein, Mary, and Constance Kostelac. 2002. Lavender and blue: Attitudes about homosexuality and behavior towards lesbians and gay men among police officers. Journal of Contemporary Criminal Justice 18: 302-28. [CrossRef]

Bernstein, Mary, and Paul Swartwout. 2012. Gay officers in their midst: Heterosexual police employees' anticipation of the consequences for coworkers who come out. The Journal of Homosexuality 59: 1145-66. [CrossRef] [PubMed]

Berrill, Kevin. 1993. Anti-gay violence: Causes, consequences, and responses. In Bias Crime: American Law Enforcement and Legal Responses. Edited by Robert J. Kelly. Chicago: University of Illinois at Chicago Press, pp. 151-64.

Berrill, Kevin T., and Gregory M. Herek. 1992. Primary and secondary victimization in anti-gay hate crimes. In Hate Crimes. Edited by Gregory Herek and Kevin T. Berrill. Thousand Oaks: SAGE, pp. 289-305. 
Braga, Anthony B., Christopher Winship, Tom R. Tyler, Jeffrey Fagan, and Tracey L. Meares. 2014. The salience of social contextual factors in appraisals of police interactions with citizens: A randomized factorial experiment. Journal of Quantitative Criminology 30: 599-627. [CrossRef]

Briones-Robinson, Rhissa, Ráchael A. Powers, and Kelly M. Socia. 2016. Sexual orientation bias crimes: Examination of reporting, perception of police bias, and differential police response. Criminal Justice Behavior 43: 1688-709. [CrossRef]

Brunson, Rod K. 2007. "Police don't like black people." African-American young men's accumulated police experiences. Criminology and Public Policy 6: 71-102. [CrossRef]

Brunson, Rod K., and Jacinta M. Gau. 2014. Race, place, and policing in the inner-city. In The Oxford Handbook of Policing. Edited by Michael D. Reisig and Robert J. Kane. New York: Oxford University Press, pp. 362-82.

Brunson, Rod, and Jody Miller. 2006. Young Black men and urban policing in the United States. British Journal of Criminology 46: 71-102. [CrossRef]

Buist, Carrie L., and Codie Stone. 2014. Trans* victims and offenders: Failures of the United States criminal justice system and the necessity of queer criminology. Critical Criminology 22: 35-47. [CrossRef]

Burgess-Proctor, Amanda. 2006. Intersections of race, class, gender, and crime. Feminist Criminology 1: 27-47. [CrossRef]

Carpenter, Leonore F., and R. Barrett Marshall. 2017. Walking while trans: Profiling of transgender women by law enforcement, and the problem of proof. William and Mary Journal of Race, Law, and Social Justice 24: 5-38.

Carr, Patrick J., Laura Napolitano, and Janet Keating. 2007. We never call the cops and here is why: A qualitative examination of legal cynicism in three Philadelphia neighborhoods. Criminology 45: 445-80. [CrossRef]

Cagnassola, M. E. 2020. Newark creating LGBTQ hotline following Ashley Moore case. Tap Into. August 19. Available online: https: //www.tapinto.net/sections/police-and-fire/articles/newark-creating-lgbtq-hotline-following-ashley-moore-case (accessed on 6 January 2021).

Cavaliere, Victoria. 2010. Transgender Woman Sues Newark Police Over Alleged Harassment. NBC New York. February 17. Available online: https: / / www.nbcnewyork.com (accessed on 1 January 2021).

Center for American Progress. 2016. Unjust: How the Broken Criminal Justice System Fails LGBT People of Color. Washington: Center for American Progress.

Center for Constitutional Rights. 2012. Stop and Frisk: The Human Impact. New York: Center for Constitutional Rights.

Chalfin, Aaron, and Justin McCrary. 2016. Are U.S. cities underpoliced? Theory and evidence. The Review of Economics and Statistics 100: 167-86. [CrossRef]

Collins, Joshua C., and Tonette S. Rocco. 2018. Queering employee engagement to understand and improve the performance of gay male law enforcement officers: A phenomenological exploration. Performance Improvement Quarterly 30: 273-95. [CrossRef]

Colvin, Roddrick A. 2009a. Policing and Gendered Justice: Examining the Possibilities. Toronto: University of Toronto Press Inc.

Colvin, Roddrick A. 2009b. Shared perceptions among lesbian and gay police officers. Police Quarterly 12: 86-101. [CrossRef]

Colvin, Roddrick A. 2012. Gay and Lesbian Cops: Diversity and Effective Policing. London: Lynne Rienner Publishers.

Colvin, Roddrick. 2014. Policing the lesbian and gay community: The perceptions of lesbian and gay police officers. In Handbook of LGBT Communities, Crime, and Justice. Edited by Dana Peterson and Vanessa Panfil. New York: Springer, pp. $183-205$.

Courvant, Diane, and Loree Cook-Daniels. 1998. Trans and Intersex Survivors of Domestic Violence: Defining Terms, Barriers, and Responsibilities. National Coalition of Domestic Violence. Available online: http://www.survivorproject.org/ (accessed on 1 January 2021).

Crenshaw, Kimberlé. 1991a. Demarginalizing the intersection of race and sex: A black feminist critique of antidiscrimination doctrine, feminist theory and antiracist politics. In Feminist Legal Theory: Readings in Law and Gender, 1st ed. Edited by Katharine Bartlett and Rosanne Kennedy. New York: Taylor and Francis, pp. 57-80.

Crenshaw, Kimberlé. 1991b. Mapping the margins: Intersectionality, identity politics, and violence against women of color. Stanford Law Review 43: 1241-99. [CrossRef]

Dario, Lisa M., Henry F. Fradella, Megan Verhagen, and Megan M. Parry. 2019. Assessing LGBT people's perceptions of police legitimacy. Journal of Homosexuality 67: 1-31. [CrossRef]

Deschamps, David, and Bennett Singer. 2017. LGBTQ Stats: Lesbian, Gay, Bisexual, Trans*, and Queer People by the Numbers. New York: The New Press.

Di Ionno, Mark. 2020. Latest consent decree quarterly report highlights Newark police improvements. In City of Newark Communication; February 5. Available online: https:/ / www.newarknj.gov/news/latest-consent-decree-quarterly-report-highlights-newarkpolice-improvements (accessed on 1 January 2021).

DOJ. 2014. Investigation of the Newark Police Department; City of Newark: The United States Department of Justice Civil Rights Division and the United States Attorney's Office.

DOJ. 2017. An Interactive Guide to the Civil Rights Division's Police Reforms. The Civil Rights Division of the Department of Justice. Available online: https:/ / www.justice.gov/crt/page/file/922456/download (accessed on 1 January 2021).

Dunbar, Edward. 2006. Race, gender, and sexual orientation in hate crime victimization: Identity politics or identity risk? Violence and Victims 21: 323-37. [CrossRef]

Dwyer, Angela. 2007. Policing lesbian, gay, bisexual, and trans* young people: A gap in the research literature. Current Issues in Criminal Justice 22: 415-33. [CrossRef] 
Dwyer, Angela. 2019. Queering policing: What is the best practice with LGBTQ communities? Current Issues in Criminal Justice 31: 396-411. [CrossRef]

Essex LGBT Reaching Adolescents in Need. 2017. Community Partners. LGBT Rain Foundation. Available online: http:// essexlgbthousing.org/community-partners/ (accessed on 1 January 2021).

Federal Bureau of Investigation. 2018a. 2018 Hate Crime Statistics; Washington: Criminal Justice Information Services Division.

Federal Bureau of Investigation. 2018b. Crime in the United States. 2018; Washington: Criminal Justice Information Services Division.

Federal Bureau of Investigation. 2020. Crime in the United States. 2019; Washington: Criminal Justice Information Services Division.

Feinstein, Randi, Andrea Greenblatt, Lauren Hass, Sally Kohn, and Julianne Rana. 2001. Justice for All? A Report on Lesbian, Gay, Bisexual, and Transgendered Youth in the New York Juvenile Justice System. New York: The Lesbian and Gay Youth Project of the Urban Justice Center.

Gaynor, Tia, and Brandi Bassett. 2020. Deviance in policing and the mistreatment of LGBTQ people of color. In Deviance Today. Edited by Addrain Conyers and Thomas C. Calhoun. New York: Routledge, pp. 146-61.

Gerhardt, Ashley. 2016. What we learned from Frontline's Policing the Police about the Newark Police Department. Brick City Live. July 1. Available online: https:// brickcitylive.com/news/ashleygerhardt/what-we-learned-from-frontlines-policing-the-policenewark-pd/ (accessed on 1 January 2021).

Graham, Louis F. 2014. Navigating community institutions: Black transgender women's experiences in schools, the criminal justice system, and churches. Sexuality Research and Social Policy 11: 274-87. [CrossRef]

Grant, Jaime, Lisa Mottet, Justin Tanis, Jack Harrison, Jody L. Herman, and Mara Jeislin. 2011. Injustice at Every Turn: A Report of the National Trans* Discrimination Survey. Washington: National Center for Trans* Equality and National Gay and Lesbian Task Force.

Guadalupe-Diaz, Xavier L. 2016. Disclosure of same-sex intimate partner violence to police among lesbians, gays, and bisexuals. Social Currents 3: 160-71. [CrossRef]

Guadalupe-Diaz, Xavier L., and Jana Jasinski. 2017. I wasn't a priority, I wasn't a victim: Challenges in help seeking for trans* survivors of intimate partner violence. Violence Against Women 23: 772-92. [CrossRef] [PubMed]

Guadalupe-Diaz, Xavier L., and Jonathan Yglesias. 2013. “Who's protected?" Exploring perceptions of domestic violence by lesbians, gays, and bisexuals. Journal of Gay E Lesbian Social Services 25: 465-85. [CrossRef]

Hassouneh, Dena, and Nancy Glass. 2008. The influence of gender role stereotyping on women's experiences of female same-sex intimate partner violence. Violence Against Women 14: 310-25. [CrossRef]

Herek, Gregory M. 1989. Hate crimes against lesbians and gay men: Issues for research and policy. American Psychologist 44: 948-55. [CrossRef]

Herek, Gregory M. 2009. Hate crimes and stigma-related experiences among sexual minority adults in the United States: Prevalence estimates from a national probability sample. Journal of Interpersonal Violence 24: 54-74. [CrossRef]

Herek, Gregory M., Kevin T. Berrill, and Kevin Berrill. 1992. Hate Crimes: Confronting Violence against Lesbians and Gay Men. Thousand Oaks: SAGE.

Herek, Gregory M., Jeanine C. Cogan, and J. Roy Gillis. 2002. Victim experiences in hate crimes based on sexual orientation. Journal of Social Issues 58: 319-39. [CrossRef]

Hirschel, David, and Philip D. McCormack. 2020. Same-sex couples and the police: A 10-year study of arrest and dual arrest rates in responding to incidents of intimate partner violence. Violence Against Women, 1-31. [CrossRef]

Hodge, Jessica P., and Lori Sexton. 2018. Examining the blue line in the rainbow: The interactions and perceptions of law enforcement among lesbian, gay, bisexual, trans*, and queer communities. Police Practice and Research 19: 1-18. [CrossRef]

Holsinger, Kristi, and Jessica P. Hodge. 2016. The experiences of lesbian, gay, bisexual, and transgender girls in juvenile justice systems. Feminist Criminology 11: 23-47. [CrossRef]

Huebner, David M., Gregory M. Rebchook, and Susan M. Kegeles. 2004. Experiences of harassment, discrimination, and physical violence among young gay and bisexual men. American Journal of Public Health 94: 1200. [CrossRef] [PubMed]

Human Rights Campaign. 2014. A Resource Guide to Coming Out. The Human Rights Campaign Foundation. Available online: https: / / www.hrc.org/resources (accessed on 1 January 2021).

Ingram, Jason R., William Terrill, and Eugene G. Paoline. 2018. Police culture and officer behavior: Applications of a multilevel framework. Criminology 56: 780-811. [CrossRef]

Israel, Tania, Audrey Harkness, Todd R. Avellar, Kevin Delucio, Jay N. Bettergarcia, and Joshua A. Goodman. 2016. LGBTQ-Affirming policing: Tactics generated by law enforcement personnel. Journal of Police Criminal Psychology 31: 173-81. [CrossRef]

James, Sandy E., Jody L. Herman, Susan Rankin, Mara Keisling, Lisa Mottet, and Ma'ayan Anafi. 2016. The Report of the 2015 U.S. Transgender Survey. Washington, DC: National Center for Transgender Equality.

Jauk, Daniela. 2013. Gender violence revisited: Lessons from violent victimization of transgender identified individuals. Sexualities 16: 807-25. [CrossRef]

Katz-Wise, Sabra L., and Janet S. Hyde. 2012. Victimization experiences of lesbian, gay, and bisexual individuals: A meta-analysis. Journal of Sex Research 49: 142-67. [CrossRef]

Kershner, Ellen. 2020. The largest police departments in the US. WorldAtlas. August 3. Available online: https://www.worldatlas.com/ articles/the-largest-police-departments-in-the-us.html (accessed on 1 January 2021).

Kieffer, Eric. 2020. Newark will take $\$ 12 \mathrm{~m}$ from police, reinvest in social services. Patch. June 25. Available online: https://patch.com/ new-jersey/newarknj/newark-will-take-12m-police-reinvest-social-services (accessed on 1 January 2021). 
Kuehnle, Kristen, and Anne Sullivan. 2001. Patterns of anti-gay violence: An analysis of incident characteristics and victim reporting. Journal of Interpersonal Violence 16: 928-43. [CrossRef]

Lambda Legal. 2015. Protected and Served? New York: Lambda Legal.

Langenderfer-Magruder, Lisa, Darren L. Whitfield, N. Eugene Walls, Shanna Kattari, and Daniel Ramos. 2016a. Experiences of intimate partner violence and subsequent police reporting among lesbian, gay, bisexual, transgender, and queer adults in Colorado: Comparing rates of cisgender and transgender victimization. Journal of Interpersonal Violence 31: 855-71. [CrossRef]

Langenderfer-Magruder, Lisa, N. Eugene Walls, Shanna K. Kattari, and Darren L. Whifield. 2016b. Sexual victimization and subsequent police reporting among lesbian, gay, bisexual, and queer adults. Violence and Victims 31: 320-31. [CrossRef]

Langton, Lynn, Marcus Berzofsky, Christopher Krebs, and Hope Smiley-McDonald. 2012. Victimizations Not Reported to the Police. 2006-2010 (No. NCJ 238536). Washington: The Bureau of Justice Statistics.

Larsen, James E., and John P. Blair. 2009. The importance of police performance as a determinant of satisfaction with the police. American Journal of Economics and Business Administration 1: 1-10. [CrossRef]

Lee, Jae-Seung, Jonathan Lee, and Larry T. Hoover. 2014. What conditions affect police response time? Examining situational and neighborhood factors. Police Quarterly 20: 61-80. [CrossRef]

Levin, Sam. 2020. Movement to defund police gains 'unprecedented' support across US. The Guardian. June 4. Available online: https:/ / www.theguardian.com/us-news/2020/jun/04/defund-the-police-us-george-floyd-budgets (accessed on 7 January 2021).

Levitt, Steven D. 2002. Using electoral cycles in police hiring to estimate the effects of police on crime: Reply. The American Economic Review 92: 1244-50. [CrossRef]

Lombardi, Emilia, Riki A. Wilchins, Dana Priesing, and Diana Malouf. 2001. Gender violence: Trans* experiences with violence and discrimination. Journal of Homosexuality 42: 89-101. [CrossRef] [PubMed]

Lyons, Phillip M., Christine M. Anthony, Karen M. Davis, Krissie Fernandez, Angela N. Torres, and David K. Marcus. 2005. Police judgments of culpability and homophobia. Applied Psychology in Criminal Justice 1: 1-14.

Lyons, Phillip M., Michael DeValve, and Randall L. Gardner. 2008. Texas police chiefs' attitudes toward gay and lesbian police officers. Police Quarterly 11: 102-17. [CrossRef]

Mallory, Christy, Amira Hasenbush, and Brad Sears. 2013. Discrimination Against Law Enforcement Officers on the Basis of Sexual Orientation and Gender Identity: 2000 to 2013. Los Angeles: The Williams Institute.

Mallory, Christy, Amira Hasenbush, and Brad Sears. 2015. Discrimination and Harassment by Law Enforcement Officers in the LGBT Community. Los Angeles: The Williams Institute.

Masucci, Madeline, and Lynn Langton. 2017. Hate Crime Victimization. 2004-2015 (No. NCJ 250653). Washington: The Bureau of Justice Statistics.

Matthes, Anja, and Sony Salzman. 2019. In the kiki ballroom scene, queer kids of color can be themselves. The Atlantic. November 7. Available online: https:/ / www.theatlantic.com/photo/2019/11/nyc-kiki-community/599830/ (accessed on 7 January 2021).

McCabe, James E., and Paul E. O'Connell. 2017. Factors related to police staffing. International Journal of Humanities and Social Science Review 3: 1-14.

McCarthy, Justin. 2019. U.S. Support for Gay Marriage Stable, at 63\%. Gallup. May 22. Available online: news.gallup.com (accessed on 1 January 2021).

Messinger, Adam M. 2017. LGBTQ Intimate Partner Violence: Lessons for Policy, Practice, and Research. Oakland: University of California Press.

Meyer, Doug. 2010. Evaluating the severity of hate-motivated violence: Intersectional differences among victims. Sociology 44: 980-55. [CrossRef]

Meyer, Ilan H., Andrew R. Flores, Lara Stemple, Adam P. Romero, Bianca D. M. Wilson, and Jody L. Herman. 2017. Incarceration rates and traits of sexual minorities in the United States: National Inmate Survey. 2011-2012. American Journal of Public Health 107: 267-73. [CrossRef]

Miles-Johnson, Toby. 2013a. Confidence and trust in the police: How sexual identity difference shapes perceptions of police. Current Issues in Criminal Justice 25: 685-702. [CrossRef]

Miles-Johnson, Toby. 2013b. LGBTI variations in crime reporting: How sexual identity influences decisions to call the cops. SAGE Open 3: 1-15. [CrossRef]

Miles-Johnson, Toby. 2016. Perceptions of group value: How Australian transgender people view policing. Policing and Society: An International Journal of Research and Policy 26: 605-26. [CrossRef]

Miles-Johnson, Toby. 2020. Policing transgender people and intimate partner violence (IPV). In Intimate Partner Violence and the LGBT+ Community. Edited by Brenda Russell. Reading: Springer Publications, pp. 281-304.

Miller, Susan L., Kay B. Forest, and Nancy C. Jurik. 2003. Diversity in blue: Lesbian and gay police officers in a masculine occupation. Men and Masculinities 5: 355-85. [CrossRef]

Mogul, Joey L., Andrea Ritchie, and Kay Whitlock. 2011. Queer (In)justice: The Criminalization of LGBT People in the United States. Boston: Beacon Press.

Moran, Leslie J., and Andrew N. Sharpe. 2004. Violence, identity, and policing: The case of violence against transgender people. Criminal Justice 4: 395-417. [CrossRef]

Muraco, Anna. 2006. Intentional families: Fictive kin ties between cross-gender, different sexual orientation friends. Journal of Marriage and Family 68: 1313-25. [CrossRef] 
Nadal, Kevin L., Amalia Quintanilla, Ariana Goswick, and Julie Striken. 2015. Lesbian, gay, bisexual, and queer people's perceptions of the criminal justice system: Implications for social services. Journal of Gay and Lesbian Social Services 27: 457-81. [CrossRef]

NCVAP. 2017a. Lesbian, Gay, Bisexual, Transgender, Queer, and HIV-Affected Hate Violence in 2016. New York: National Coalition of Anti-Violence Programs.

NCVAP. 2017b. Lesbian, Gay, Bisexual, Transgender, Queer, and HIV-Affected Intimate Partner Violence in 2016. New York: National Coalition of Anti-Violence Programs.

NCVAP. 2018. Lesbian, Gay, Bisexual, Transgender, Queer, and HIV-Affected Hate and Intimate Partner Violence in 2017. New York: National Coalition of Anti-Violence Programs.

Nelson, Blake. 2019a. Newark police blazing trail with new protections for transgender suspects. NJ Advance Media for NJ.com. April 17. Available online: https:// www.nj.com/news/2019/04/newark-police-blazing-trail-with-new-protections-for-transgendersuspects.html (accessed on 1 January 2021).

Nelson, Blake. 2019b. Residents want cops to respond in less than 30 minutes, but that's still not happening in N.J.'s biggest city: Report. NJ Advance Media for NJ.com. April 16. Available online: https:/ /www.nj.com/news/2019/04/residents-want-cops-torespond-in-less-than-30-minutes-but-thats-still-not-happening-in-njs-biggest-city-report.html (accessed on 1 January 2021).

Newark Department of Public Safety. 2018. The City of Newark. Available online: https://www.newarknj.gov/departments/publicsafety (accessed on 1 January 2021).

Newark Police Division. 2020. Newark Police Consent Decree and Planning Division. Newark: City of Newark Department of Public Safety, Available online: https:/ / www.npdconsentdecree.org/city-of-newark-consent-decree (accessed on 1 January 2021).

O'Dea, Colleen. 2019. NJ police get new guidelines, training on interacting with transgender people. NJ Spotlight News. November 21. Available online: https:/ / www.njspotlight.com/2019/11/nj-police-get-new-guidelines-training-on-interacting-withtransgender-people/ (accessed on 1 January 2021).

Oudekerk, Barbara A. 2019. Hate Crime Statistics [PowerPoint Slides]. Available online: https:/ /www.bjs.gov (accessed on 1 January 2021).

Owen, Stephen S., Tod W. Burke, April L. Few-Demo, and Jameson Natwick. 2018. Perceptions of the police by LGBT communities. American Journal of Criminal Justice 43: 668-93. [CrossRef]

Panfil, Vanessa. 2018. LGBTQ populations of color, crime, and justice: An emerging but urgent topic. In The Handbook of Race, Ethnicity, Crime, and Justice. Edited by Ramiro Martinez, Meghan E. Hollis and Jacob I. Stowell. Hoboken: Wiley Blackwell, pp. 415-34.

Panfil, Vanessa, and Jody Miller. 2014. Beyond the straight and narrow: The import of queer criminology for criminology and criminal justice. The Criminologist 39: 1-9.

Panter, Heather. 2018. Transgender Cops: The Intersection of Gender and Sexuality Expectations in Police Cultures. New York: Routledge.

Peel, Elizabeth. 1999. Violence against lesbians and gay men: Decision-making in reporting and not reporting crime. Feminism and Psychology 9: 161-67. [CrossRef]

Peyton, Kyle, Michael Sierra-Arévalo, and David G. Rand. 2019. A field experiment on community policing and police legitimacy. Proceedings of the National Academy of Sciences of the United States of America 116: 19894-98. [CrossRef]

Pezella, Frank S., Matthew D. Fetzer, and Tyler Keller. 2019. The dark figure of hate crime underreporting. American Behavioral Scientist, 1-24. [CrossRef]

Rahman, Rema. 2019. 89 Newark police recruits welcomed to training academy. TAP IP LLC. September 18. Available online: https://www.tapinto.net/towns/newark/sections/police-and-fire/articles/89-newark-police-recruits-welcomed-totraining-academy (accessed on 1 January 2021).

Rengifo, Andres F., and Jennifer Fratello. 2015. Perceptions of the police by immigrant youth: Looking at stop-and-frisk and beyond using a New York City sample. Youth Violence and Juvenile Justice 13: 409-27. [CrossRef]

Robinson, Brandon Andrew. 2020. The lavender scare in homonormative times: Policing, hyper-incarceration, and LGBTQ youth homelessness. Gender and Society 34: 210-32. [CrossRef]

Rollè, Luca, Giulia Giardina, Angela Caldarera, Eva Gerino, and Piera Brustia. 2018. When intimate partner vioence meets same sex couples: A review of same sex intimate partner violence. Frontiers in Psychology 9: 1-13. [CrossRef]

Rosenbaum, Dennis P., Amie M. Schuck, Sandra K. Costello, Darnell F. Hawkins, and Marianne K. Ring. 2005. Attitudes toward the police: The effects of direct and vicarious experience. Police Quarterly 8: 343-65. [CrossRef]

Ross, Dax-Devlon. 2019. One city's struggle to police the police. The Washington Post Magazine. December 19. Available online: https:/ / www.washingtonpost.com/magazine/2019/12/04/obama-administration-ordered-newark-fix-its-police-force-hereswhat-has-hasnt-happened/?arc404=true (accessed on 1 January 2021).

Rothman, Emily F., Deinera Exner, and Allyson L. Baughman. 2011. The prevalence of sexual assault against people who identify as gay, lesbian, or bisexual in the United States: A systematic review. Trauma, Violence, and Abuse 12: 55-66. [CrossRef]

Rutgers School of Public Health. 2019. Rutgers dean appointed to Newark's LGBTQ Commission. Newswise. March 14. Available online: https:/ / www.newswise.com/articles/rutgers-dean-appointed-to-newark-s-lgbtq-commission (accessed on 1 January 2021).

Satuluri, Sriya, and Kevin L. Nadal. 2018. LGBTQ perceptions of the police: Implications for mental health and public policy. LGBTQ Policy Journal 8: 43-55.

Serpe, Christine R., and Kevin L. Nadal. 2017. Perceptions of police: Experiences in the trans* community. Journal of Gay and Lesbian Social Services 29: 280-99. [CrossRef] 
Shearn, Ian T. 2020. Ras Baraka: Struggling to rebuild the police force in Newark's image. NJ Spotlight Nerws. September 1. Available online: https:/ / www.njspotlight.com/2020/09/newark-baraka-mayor-police-force-civilian-review-diversity-racism/ (accessed on 1 January 2021).

Smith, Eric L., and Alexia D. Cooper. 2020. Offenses Known to Law Enforcement in Large Cities. 2018: Select Findings from the FBI's Uniform Crime Reporting Program (No. NCJ 254502). Washington: The Bureau of Justice Statistics.

Spradley, James P. 1979. The Ethnographic Interview. Belmont: Wadsworth Cengage Learning.

Stotzer, Rebecca L. 2009. Violence against trans* people: A review of United States data. Aggression and Violent Behavior 14: 170-79. [CrossRef]

Stotzer, Rebecca L. 2014a. Bias crimes based on sexual orientation and gender identity: Global prevalence, impacts, and causes. In Handbook of LGBT Communities, Crime, and Justice. Edited by Dana Peterson and Vanessa Panfil. New York: Springer, pp. 45-64.

Stotzer, Rebecca L. 2014b. Law enforcement and criminal justice personnel interactions with trans* people in the United States: A literature review. Aggression and Violent Behavior 19: 263-77. [CrossRef]

Stucky, Thomas D. 2005. Local politics and police strength. Justice Quarterly 22: 139-69. [CrossRef]

The Citizens Campaign. 2019. Mayor Booker swears in Newark's first LGBTQ Advisory Commission. Advance Local Media, LLC. April 1. Available online: https://www.nj.com/newark_public_blog/2009/10/mayor_booker_swears_in_newarks_first_lgbtq_advisory_ commission.html (accessed on 1 January 2021).

Tonry, Michael. 2010. The social, psychological, and political causes of racial disparities in the American Criminal Justice System. Crime and Justice 39: 273-312. [CrossRef]

Tracy, Matt. 2020. Questions mount about trans woman's suspicious death in Newark. Gay CityNews. August 19. Available online: gaycitynews.com (accessed on 1 January 2021).

Turell, Susan C., Michael Brown, and Molly Herrmann. 2017. Disproportionately high: An exploration of intimate partner violence prevalence rates for bisexual people. Sexual and Relationship Therapy 33: 113-31. [CrossRef]

Turell, Susan C. 2000. A descriptive analysis of same-sex relationship violence for a diverse sample. Journal of Family Violence 15: 281-93. [CrossRef]

United States Census Bureau. 2017. American Fact Finder. Available online: www.factfinder.census.gov (accessed on 1 January 2021).

United States Census Bureau. 2019. QuickFacts: Newark, New Jersey; United States. Available online: https://www.census.gov/ quickfacts/fact/table/newarkcitynewjersey,US/PST045219\#qf-headnote-a (accessed on 1 January 2021).

United States v. City of New Orleans. 2013. 2:12-cv-1923-SM-JCW. Available online: https://perma.cc/T5FZ-XXPB (accessed on 1 January 2021).

United States v. City of Newark. 2016. 2:16-cv-01731-MCA-MAH. Available online: https:/ / c3bb32f4-4b49-462c-abf8-5d2c1d510fe0 .filesusr.com/ugd/582c35_d6952c9a322c47668aface670550d8eb.pdf (accessed on 1 January 2021).

United States v. Police of Baltimore City. 2017. 1:17-cv-00099-JKB. Available online: https:/ / perma.cc/9Z7J-JM87 (accessed on 1 January 2021).

Weitzer, Ronald, and Steven A. Tuch. 2005. Determinants of public satisfaction with the police. Police Quarterly 8: 279-97. [CrossRef]

Whitfield, Darren L., Robert W. S. Coulter, Lisa Langenderfer-Magruder, and Daniel Jacobson. 2018. Coulter, Lisa LangenderferMagruder, and Daniel Jacobson. 2018. Experiences of intimate partner violence among lesbian, gay, bisexual, and transgender college students: The intersection of gender, race, and sexual orientation. Journal of Interpersonal Violence, 1-25. [CrossRef]

Wilson, Michael, and Serge F. Kovaleski. 2010. A fatal encounter in a Newark park. The New York Times. August 20. Available online: www.nytimes.com (accessed on 1 January 2021).

Wilson, Jeremy M., and Alexander Weiss. 2014. A Performance-Based Approach to Police Staffing and Allocation. Washington: Officer of Community Oriented Policing Services.

Wilson, Jeremy M., Erin Dalton, Charles Scheer, and Clifford A. Grammich. 2010. Police Recruitment and Retention for the New Millennium: The State of Knowledge. Santa Monica: RAND Corporation.

Wolff, Kristina B., and Carrie L. Cokely. 2007. "To protect and serve?": An exploration of police conduct in relation to the gay, lesbian, bisexual, and trans* community. Sex Culture 11: 1-23. [CrossRef]

Woods, Jordan Blair. 2014. "Queering criminology": Overview of the state of the field. In Handbook of LGBT Communities, Crime, and Justice. Edited by Dana Peterson and Vanessa Panfil. New York: Springer, pp. 15-41.

Woods, Jordan Blair, Frank H. Galvan, Moshen Bazargan, Jody L. Herman, and Ying-Tung Chen. 2013. Latina transgender women's interactions with law enforcement in Los Angeles county. Policing 7: 379-91. [CrossRef]

Xie, Min, Greg Pogarsky, James P. Lynch, and David McDowall. 2007. Prior police contact and subsequent victim reporting: Results from the NCVS. Justice Quarterly 23: 481-501. [CrossRef] 